\begin{tabular}{|l|l|c|c|}
\hline Eiszeitalter u. Gegenwart & 34 & $105-129$ & Hannover 1984 \\
\hline
\end{tabular}

\title{
Zur jungpleistozänen und holozänen Entwicklung des Werratals zwischen Hannoversch-Münden und Philippsthal (östl. Bad Hersfeld)
}

\author{
KARL-ULRICH BROSCHE* \\ Herrn Prof. Dr. W. WÖHLKE zum 60. Geburtstag gewidmet \\ Development, Werra Valley, lower terrace, gravel, finer grained sediment, fluvial history, Late \\ Glacial, Early Holocene, peat bog, former channel, meadow loam, black meadow soil, loess." \\ Hessen Depression, Witzenhausen Altenburschla Region, Hessen. \\ TK 25 Nr.: 4625, 4725
}

\begin{abstract}
Kurzf assung: Im unteren und mittleren Werratal läßt sich eine 5-8 $\mathrm{m}$ ü. Talaue gelegene Terrasse ausgliedern, die an mehreren Lokalitäten eine weite Verbreitung hat und aufgrund ihres Aufbaus und ihrer Deckschichten (z.T. Löß) als hochwürmzeitliche Niederterrasse eingestuft wird. Sie wurde schon im Spätglazial durch 0,5-1,0 m tiefen Rinnen zerschnitten, die von wahrscheinlich umgelagerten Niederterrassenschottern oder feinkörnigeren Sedimenten wieder aufgefüllt wurden. Die spätglaziale und frühholozäne Flußgeschichte läßt sich dank zeitweilig günstiger Aufschlußverhältnisse bei Eschwege recht gut rekonstruieren (Abb. 6 und 7). Dies gelingt hier besser als im Werraabschnitt auf dem Gebiet der DDR, der von ELLENBERG (1967 bis 1975) sehr genau untersucht worden ist. „Ried“ablagerungen in ehemaligen Werrarinnen können präallerödzeitlichen und jungtundrenzeitlichen bis borealen Alters sein. Wie im Leinetal finden sich im Werratal zwei verschieden alte Auelehme, von denen der ältere stellenweise eine wahrscheinlich dem postglazialen Klimaoptimum zuzuordnende Auen-Schwarzerde trägt. In den „Ried“ablagerungen konnten 12 Flußmuschel- bzw. -schneckenarten gefunden und bestimmt werden.
\end{abstract}

\section{Investigations into the Late Pleistocene and Holocene \\ Development of the Werra Valley between Hannoversch-Münden and Philippsthal (east of Bad Hersfeld)}

In the lower and middle Werra valley a terrace is located $5-8 \mathrm{~m}$ above the valley plain. It attains a considerable width in several places, its structure and overburden (sometimes loess) indicate a High Wuermian lower terrace. Probably during the Late Glacial it was dissected by $0.5-1.0 \mathrm{~m}$ deep chan-

* Anschrift des Autors: Priv.-Dozent Dr. K.-U. Brosche, Institut f. Physische Geographie der Freien Universität Berlin, Grunewaldstr. 35, 1000 Berlin 41.

Herrn Prof. Dr. E. Bibus, Tübingen, und Herrn Dr. Scheer, Frankfurt, danke ich für die Untersuchung mehrerer Tuffproben, die ich erstmals 1974 in mehreren Aufschlüssen des Werratales in der Umgebung von Eschwege fand. Herrn Dr. H. Sснüтt, Düsseldorf, gilt mein Dank für die Bestimmung von Flußmuscheln und -schnecken. Dem Ehepaar Dölle, Standquartier für Erdwissenschaften der FU Berlin Eschwege, danke ich herzlich für die jahrelange Unterstützung bei meinen Untersuchungen im Eschweger Gebiet. Herrn Wiss. Ass. Dr. M. WaltheR, Berlin, danke ich für den Hinweis auf den Aufschluß bei Freudenthal. 
nels, which were subsequently infilled by probably redeposited lower-terrace gravel or finer-grained sediment. Owing to temporarily accessible exposures near Eschwege, the Late Glacial and Early Holocene fluvial history may be reconstructed more satisfactorily here than in the GDR section of the Werra, which ElLENBERG investigated thoroughly (1967-1975). "Ried" (peat bog) deposits in former Werra channels may be pre-Alleröd and early Tundra to Boreal in age. Like the Leine valley, the Werra valley contains two "Auelehme" (meadow loam) of different ages, the older of which is covered in places by an "Auen-Schwarzerde" (black meadow soil), probably formed during the postglacial climatic optimum. Twelve species of river molluscs were found and determined.

\section{Inhaltsverzeichnis}

1. Einleitung: Untersuchungsgebiet, Problemstellung und Literaturüberblick

2. Die Werra-Niederterrasse und die Talaue

2.1. Einführung und Überblick

2.2 Die 5- bis 8-m-Trasse

3. Die spätglaziale und holozäne Überformung des Werratalbodens

3.1 Einleitung

3.2 Der Ried bei Eschwege und Schwebda

3.3. Ältere Schotterumlagerungen und Schotterrinnen über dem Werra-NiederterrassenSchotterkörper

3.4 Die spätglaziale Überformung des Werratalbodens durch Rinnen

3.5 Schichtfolgen-Variante

4. Zusammenfassung

5. Schriftenverzeichnis

\section{Einleitung: \\ Untersuchungsgebiet, Problemstellung und Literaturüberblick}

Untersuchungsgebiet ist das mittlere und untere Werratal, d.h. der Talabschnitt zwischen Hannoversch-Münden und Heldra (südl. Wanfried) sowie die zur Bundesrepublik Deutschland gehörenden Talabschnitte zwischen Herleshausen und Wommen, bei Kleinensee, bei Obersuhl sowie zwischen Widdershausen und Philippsthal östl. Bad Hersfeld.

In diesem Untersuchungsraum wurden in den Jahren 1968 bis 1979 alle Aufschlüsse systematisch beobachtet und aufgenommen. Viele davon sind in der Zwischenzeit wieder verschwunden. Im Mittelterrassenbereich, der ebenfalls untersucht wurde, aber hier noch ausgespart bleibt, wurden in verschiedenen Aufschlüssen Aufgrabungen und Bohrungen durchgeführt, um die häufig in einiger Tiefe befindlichen Felssockel zu erreichen (Tab. 2).

Im Niederterrassenbereich findet z.Z. die hauptsächliche Ausbeutung des sehr geschätzten - weil Grundgebirgsschotter enthaltenden - Werrakieses statt, so daß hier eine große Anzahl von Kiesgruben aufgenommen werden konnte. Diese befinden bzw. befanden sich zum überwiegenden Teil zwischen Bad Sooden-Allendorf und Wanfried, während das untere Werratal, dem die Studie von MENSCHING (1953) gewidmet ist, zwischen 1968 und 1979 sehr wenige brauchbare Aufschlüsse aufwies. Durch das Abpumpen des Grundwassers 
in einigen Niederterrassenschotter-Gruben im Raume Eschwege war es möglich, den Niederterrassenschotterkörper und seine Deckschichten bis auf den liegenden Felssockel hinab zu verfolgen.

Unter den älteren Arbeiten verdient die Studie von MeINECKE (1913) besondere Beachtung, da der Autor das gesamte Werratal systematisch nach Schotterkörpern absuchte und detaillierte Kartierungen vornahm. In dieser Arbeit finden vor allem die älteren Terrassen und Schotterkörper Beachtung.

Die erste Werratalarbeit mit klimatisch-morphologischer Fragestellung legte MENSCHING (1953) für das untere Werratal vor, wobei er seine Beobachtungen auf die 50- bis 55-m-Terrasse und die jüngeren Terrassen beschränkt und eine periglazialmorphologische Kartierung des gesamten Tal- und Hangbereiches zwischen Hedemünden und Bad Sooden-Allendorf liefert. MENSCHING (1953) unterscheidet neben dem breiten Talboden oberhalb des rezenten Flußeinschnittes, bei dem entweder Niederterrassenschotter oder holozäner Auelehm an die Oberfläche treten, eine untere Mittelterrasse, die er auch Hauptmittelterrasse nennt. Dieser etwa 4-6 m mächtige Akkumulationskörper, bei dem mehrere Meter mächtige Schotter von Flußsanden überlagert werden, liegt auf einem 3-6 m über der Talaue befindlichen Felssockel (1953: 98). Diese Hauptmittelterrasse, die sehr regelmäßig auch als morphologische Terrasse auftritt, zeigt infolge aufliegender, unterschiedlich mächtiger würmzeitlicher Schuttablagerungen nicht immer die gleiche Höhe.

Im Anschluß an die Untersuchungen von MENSCHING (1953) ist zu überprüfen, ob sich die von ihm für das untere Werratal erzielten Ergebnisse auf das mittlere Werratal übertragen lassen. Dabei stellt sich zusätzlich die Frage, ob die von Mensching (1953) in seiner Periglazial-Morphologischen Karte des unteren Werratales auskartierten rißzeitlichen Hauptmittelterrassen (z.B. bei Freudenthal bzw. Ermschwerd und bei Bad Sooden-Allendorf) als solche bestätigen lassen, oder ob es sich um würmzeitliche obere Niederterrassen handelt.

GARLEFF (1966) kommt durch Analyse der Sedimente und fossilen Böden zu dem Ergebnis, daß in der Werraweitung bei Unterrieden durch eine lokale Absenkung aufgrund von Salzauslaugung im Untergrund eine Sondersituation vorliegt. Er fand die Mittelterrassenschotter nicht auf einem deutlich über dem Werra-Talboden liegenden Felssockel, sondern stellte eine Schotterbasis unter dem Talbodenniveau fest.

Die jüngsten und modernsten Arbeiten zur Werratalgeschichte wurden von ELLENBERG (1968-1975) sowie ElLENBERG \& KUHN (1967; 1969) geliefert. Während die „Obere Niederterrasse“ mit ihrer 1 bis $2 \mathrm{~m}$ betragenden relativen Höhe in der zusammenfassenden Skizze noch in die Würmkaltzeit gestellt wird, betont EllenBERG (1968a: 697) in einem Nachtrag, daß nach weiteren Geländearbeiten, Bohrungen und besonders nach Schwermineraluntersuchungen die „Obere Niederterrasse“ (1-2 m rel. Höhe) zur Mittelterrassen-Gruppe (Saale-Kaltzeit) gestellt werden muß. Die Weichsel-Kaltzeit wird nach ELLENBERG (1968 a: 697) - ebenfalls in dem erwähnten Nachtrag - und nach ElLENBERG \& KUHN (1967) nur durch einen Niederterrassen-Schotterkörper vertreten.

Semmel (1972a: 109) berichtet dagegen vom mittleren Werratal bei Wölfershausen (östl. Bad Hersfeld), daß hier zwei würmzeitliche Niederterrassen-Schotterkörper, allerdings in einem westlichen Nebental des Hauptflusses vorkommen, wobei der ältere von Lössen bedeckt wird, in denen ein Jungwürmnaßboden, und zwar wahrscheinlich der $\mathrm{E}_{2}$-Naßboden, entwickelt ist. Diese Befunde findet Semmel (1972a) in Aufschlüssen des Maintales bestätigt.

Die zeitweilig günstigen Aufschlußverhältnisse gestatteten es mir in den Jahren 1974 bis 1979 , den allerödzeitlichen Laacher Bimstuff, den bereits RoHDENBURG (1968: 34f.) aus einem LößAufschluß bei Bischhausen am Rande des in die Werra bei Eschwege eintretenden Wehretales beschreibt, zu finden und mit seiner Hilfe das spätglaziale und frühholozäne Talgeschehen zu deuten und zu datieren.

Bei den Geländebeobachtungen wurden die Felssockel- und Schotterhöhen im Mittelterrassenkomplex genau vermessen; es wurden petrographische Analysen an jeweils 300-500 Schottern mit einem Durchmesser von $>2 \mathrm{~cm}$ durchgeführt sowie die Deckschichten der Schotter analysiert. 


\section{Die Werra-Niederterrasse und die Talaue}

\subsection{Einführung und Überblick}

Beherrschend ist im Werratal - wie in anderen mitteleuropäischen Flüssen ähnlicher Größe - ein breiter Talboden, der immer von Auelehm bedeckt ist. Er liegt in der Nähe des eigentlichen Werraeinschnitts 1,5-2,0 m über dem mittleren Wasserspiegel der Werra, steigt aber mehrfach ohne Knick auf 5-6 m über dem Wasserspiegel an. Nur teilweise läßt sich eine „Untere Niederterrasse“1) morphologisch unterscheiden, die dann mit einem 1-2 $\mathrm{m}$ hohen Hang von jenem abgetrennt ist. An verschiedenen Stellen (z.B. westl. Jestädt bei Eschwege) hat man einen Hochwasserschutzwall zwischen dem tieferen und höheren Teil des Werra-Talbodens gebaut. Zwischen beiden Teilen bestand früher ein gleichmäßig ansteigender Hang. Das oberhalb des Walles liegende, mit Feldfrüchten bestellte Gelände wird bei Hochwasser nicht mehr überflutet.

Der Werra-Talboden ist weiterhin durch eine Anzahl von nur bei Hochwasser von der Werra gespeisten Altwasserarmen gegliedert. Ein solcher mit Wasser gefüllter Altwasserarm befindet sich z.B. südwestl. Albungen, während nördlich von Albungen eine als Wiese genutzte Rinne entlang zieht, die noch heute regelmäßig bei Hochwasser von Werrawasser durchflossen wird (s. auch Kap. 3.3.).

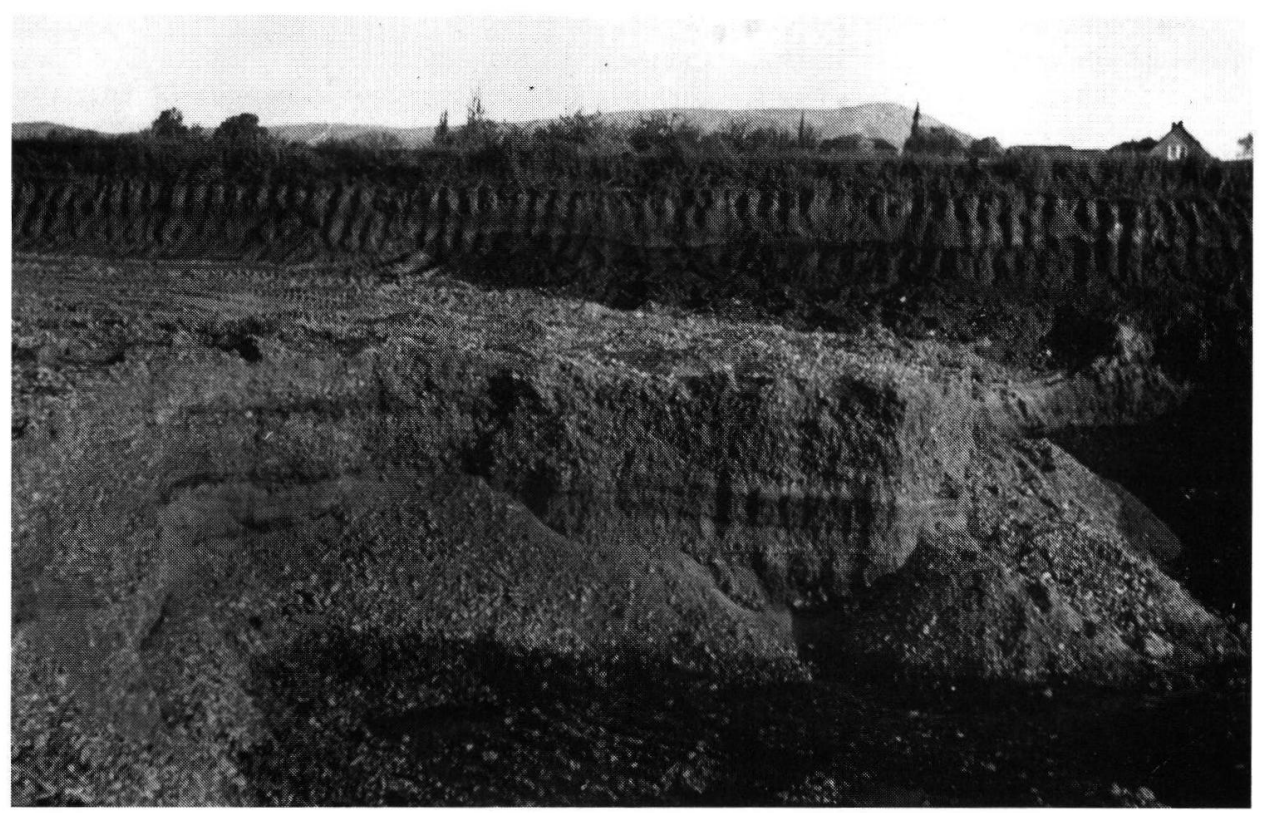

Abb. 1: Niederterrassen-Schotterkörper der Werra an der Straße Eschwege-Grebendorf südöstlich des Abzweigs der Straße nach Schwebda. Grundwasser, das ehemals bis ca. 2,0 m unter Flur hinaufreichte, künstlich durch Abpumpen abgesenkt. Zwischen Auelehm von ca. 2,0 m Mächtigkeit im Top und wohl geschichtetem Niederterrassenkörper, der auf einem Buntsandsteinfelssockel liegt, im Mittelgrund Teil einer mit Schottern aufgefüllten Rinne, die für präauelehmzeitliche Schotterumlagerungen spricht. Foto Brosche, März 1973.

1) Diese Begriffe werden hier rein beschreibend genutzt. 


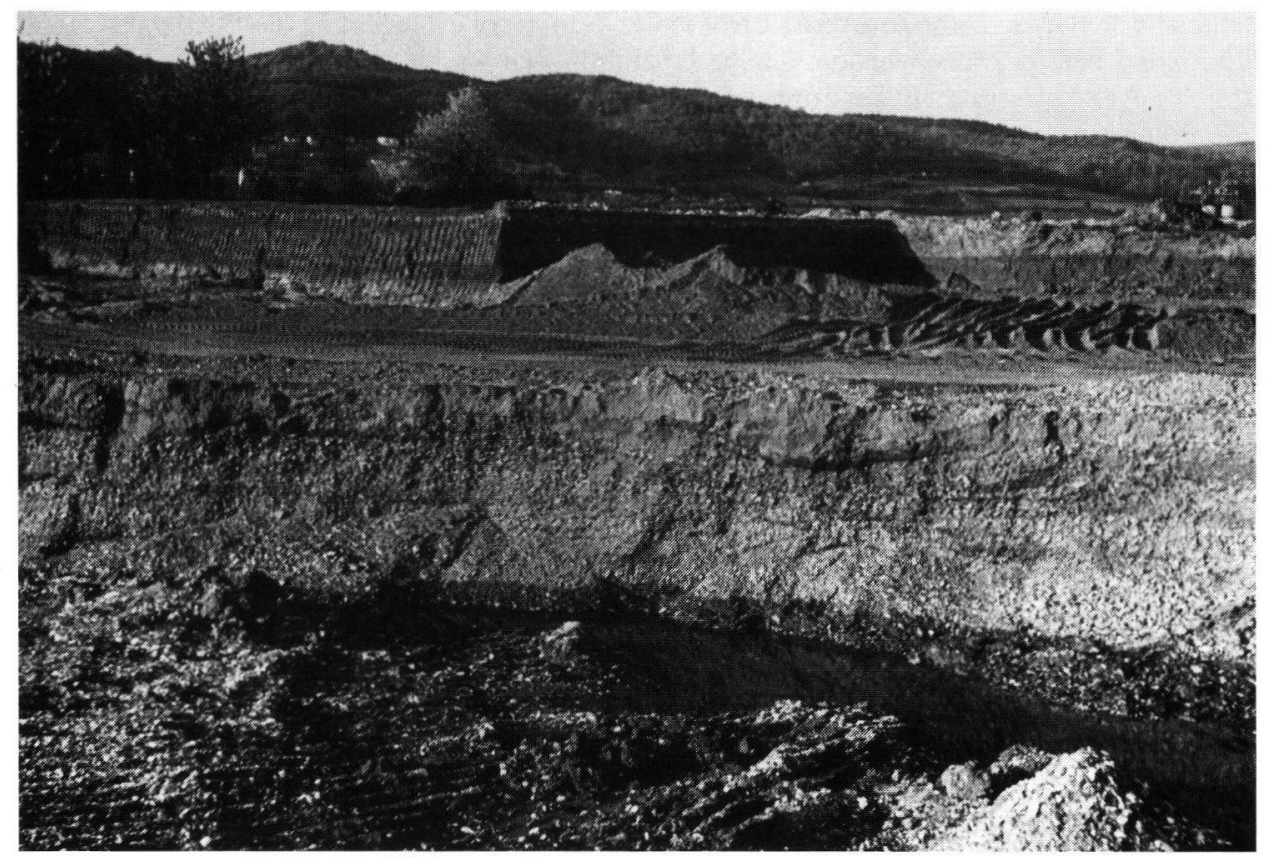

Abb. 2: Lokalität wie in Abb. 1, Blick nach $\mathrm{E}$ auf Grebendorf (Werratal). Über dem wohl geschichteten Niederterrassen-Schotterkörper, der über dem dunklen Grundwasserfleck liegt, wieder eine schmale, schottergefüllte Rinne erkennbar, an deren konvexer Unterseite humose, muddeartige Ablagerungen an ihrer Dunkelheit zu erkennen sind. Die „Rinnenschotter“ sind im Gegensatz zu den liegenden Niederterrassenschottern fast ungeschichtet und feiner. Auelehm im Hintergrund über 0,5 m „Ried“ ca. 2,0 m mächtig (vgl. Abb. 5). Foto Brosche, März 1973.

Der Niederterrassen-Schotterkörper - und hier sei bereits vorausgeschickt, daß ich keine zwei würmzeitlichen eigenständigen Schotterkörper feststellen konnte, die, durch eine Erosionsphase voneinander getrennt, aufgeschüttet worden sind - war mehrfach in Gruben bei Eschwege gut aufgeschlossen (Abb. 1 u. 2). Während in ca. 15 weiteren Niederterrassenaufschlüssen der Grundwasserspiegel so hoch hinaufreicht, daß gerade noch die oberen 0,5 bis 1,0 Meter des Niederterrassenschotters sichtbar sind, wurde in den Gruben nördlich Eschwege (nördlich und südlich der Straße Eschwege-Schwebda) der Grundwasserspiegel künstlich abgesenkt, so daß der gesamte, $3-6 \mathrm{~m}$, z.T. $8 \mathrm{~m}$ mächtige Niederterrassen-Schotterkörper ${ }^{2}$ ) sichtbar wurde. Es handelt sich um einen gut gerundeten, gut geschichteten Werraschotter, der viel Material aus dem Thüringer Wald und der Rhön enthält.

In den abgepumpten Aufschlüssen bei Eschwege (Abb. 1 u. 2) wurde jeweils der Felssockel, auf dem die Niederterrassen-Werraschotter liegen, freigelegt: Er besteht aus Ge-

2) Bei Obersuhl weist dieser eine Mächtigkeit von $16 \mathrm{~m}$, bei Widdershausen (östl. Bad Hersfeld) von $25 \mathrm{~m}$, im Gebiet von Berka (DDR) sogar von $75 \mathrm{~m}$ auf (letzteres nach ELLENBERG 1967, 1968a). Diese großen Mächtigkeiten sind allerdings auf Auslaugungsvorgänge im Zechsteinsalz zurückzuführen. $\mathrm{Ob}$ es sich dabei allein um den würmzeitlichen Schotterkörper handelt, bleibt ungeklärt. 
steinen des Unteren Buntsandsteins, die von der Werra vor Ablagerung des NiederterrassenSchotterkörpers gekappt wurden. Kleine Unebenheiten im Felssockel sind typisch, in zwei längeren Aufschlüssen ließ der Buntsandsteinsockel ein flaches, talabwärts verlaufendes Gefälle erkennen.

In der Nähe des Grundwasserspiegels läßt bzw. lassen sich fast regelmäßig ein oder mehrere rostige oder rostig-braune Oxydationsbänder feststellen. Die Schotter unter dem Oxydationsband weisen außerdem oft schwarze Mangankrusten auf, die als durchgehende Horizonte durch den Aufschluß ziehen können.

Nach Angaben von Betriebsführern und Arbeitern der den Kies ausbeutenden Firmen wurden und werden in den Schottern des Niederterrassenbereichs bei Widdershausen (östl. Bad Hersfeld), bei Schwebda, zwischen Eschwege und Schwebda und nördlich Eschwege häufig dicke Eichenbaumstämme gefunden. Bei der Bergung der Stämme war ich leider nie anwesend, so daß der genaue Entnahmepunkt nicht angegeben werden kann. Die Stämme wurden in jedem Fall aus dem Wasser gezogen und stammen wahrscheinlich aus dem Niederterrassen-Schotterkörper. Außerdem werden, wahrscheinlich auch im Niederterrassen-Schotterkörper, häufig Knochen- und Molarenreste vom Mammut gefunden.

\subsection{Die 5- bis 8 -m-Terrasse}

Neben den bereits beschriebenen morphologischen Erscheinungsbildern des Talbodenbereichs der Werra (1. allmählicher Anstieg des auelehmbedeckten Talbodens vom Flußeinschnitt auf 4-6 m Höhe über dem Werraspiegel und 2. eine kleine 1-2 $\mathrm{m}$ hohe Stufe zwischen unterem Talboden $=$ „Untere Niederterrasse“ und oberem Teil des Talbodens $=$,Obere Niederterrasse") tritt an verschiedenen Stellen ein dritter Formentyp auf: In diesem Fall schließt sich an den unteren, mit Auesand oder Auelehm bedeckten Talboden („Untere Niederterrasse“) ein 4-6 m, z.T. 6-8 m hoher Terrassenhang an, der zu einer schwach geneigten, flächig entwickelten Terrassenfläche überleitet ${ }^{3}$ ).

Es stellt sich bei dieser höheren Terrasse die Frage, ob es sich noch um eine würmzeitliche Niederterrasse handelt oder bereits um eine saalezeitliche Terrasse, wie ElLENBERG (1968: 679) und Ellenberg \& KUHN (1967) meinen und wie es auch MEnsCHING (1953, „Periglazial-Morphologische Karte des unteren Werratales“ im Anhang) z.B. für die entsprechende Terrasse bei Freudenthal (nördl. Ermschwerd - vgl. Abb. 3) und nördlich Bad Sooden-Allendorf angibt. An Lokalitäten dafür seien genannt:

a) die Terrasse, auf der der Ort Wölfershausen liegt (im Werraabschnitt Philippsthal Heringen - Widdershausen, östl. Bad Hersfeld),

b) die in mehreren Kiesgruben bei Obersuhl westlich der Werra aufgeschlossene Terrasse,

c) die Terrasse nordnordwestlich Wanfried, die von Straße und Eisenbahn benutzt wird,

d) die Terrasse westl. Aue,

e) der Schambach-Schwemmkegel bei Jestädt,

f) die Terrasse nördlich Bad Sooden-Allendorf auf der Ostseite der Werra und

g) die Terrasse nordöstl. Ermschwedt bei Freudenthal, auf der u.a. die Limnologische Flußstation liegt.

3) Dieses Terrassenniveau war bereits MeINECKE (1913) im ganzen Werratal aufgefallen und wurde von ihm kartiert. 


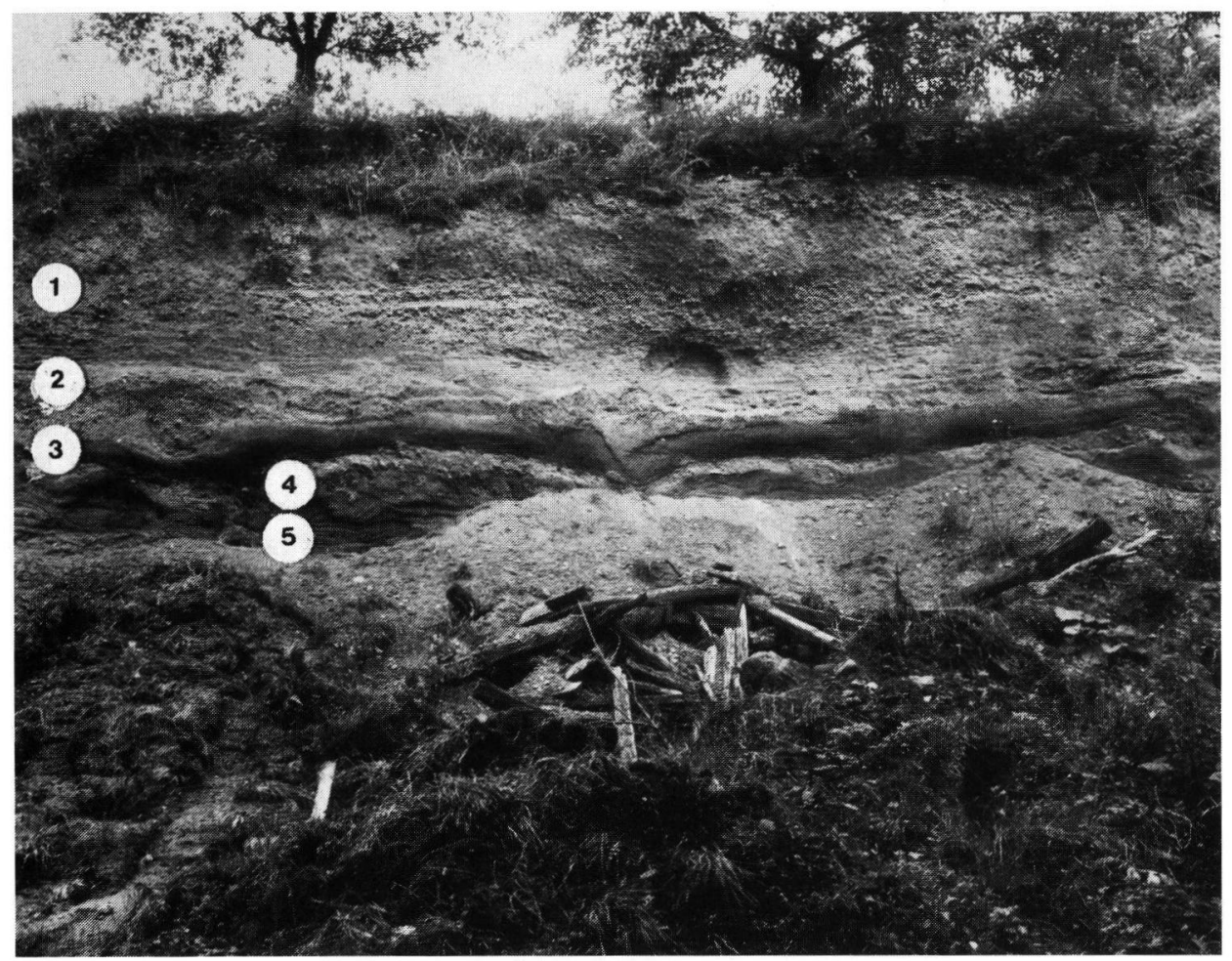

Abb. 3: Niederterrassenaufschluß in der 5- bis 8-m-Terrasse bei Freudenthal nahe der Limnologischen Flußstation. Nur die Schichten 1 bis 5 der Tabelle 1 sind klar erkennbar, während die eigentlichen Niederterrassenschotter verschüttet sind. Foto M. Walther, Berlin, 1973.

Drei der genannten Lokalitäten sowie der Schwemmfächer des Berka-Baches (Höllental) bei Albungen wurden näher untersucht. Auf der Westseite der Werra bei Obersuhl ist diese 5- bis 8-m-Terrasse weitflächig entwickelt und in mehreren Kiesgruben aufgeschlossen, in denen nach Aussagen der Arbeiter bis zu $16 \mathrm{~m}$ mächtige Werrakiese vorkommen. Bedeckt wird der Schotterkörper hier von einem 0,5-1,0 m mächtigen, gelblich-braunen, schluffigsandigen Decksediment; unter einem $A_{p}$-Horizont folgt ein pseudovergleyter Bereich. In die unteren Teile dieses schlufffigen Sandes sind aus dem liegenden Schotterkörper viele Steine aufgefroren. Zwar konnten nirgends echte Kryoturbationserscheinungen an der Schichtgrenze Schotterkörper/Schluff beobachtet werden, trotzdem sahen BIBUS und FRÄNZLE im Jahre 1973 auf einer von mir geleiteten Exkursion im Rahmen des Kasseler Geographentages in diesen aufgefrorenen Schottern die möglichen jungtundrenzeitlichen Frosteinwirkungen. Das schluffig-sandige, gelbbraune Decksediment kann mit BIBUS und FRÄNZLE ebenfalls noch als mögliches jungtundrenzeitliches Sediment angesehen werden, wobei nicht auszuschließen ist, daß im untersten pseudovergleyten Teil noch ein später überprägter Jungwürm-Naßboden auftritt. Am ehesten mögen fluvial-solifluidale Prozesse in einer letzten Lößbildungsphase der Würmkaltzeit das Sediment verlagert haben. Die 5bis 8-m-Terrasse bei Obersuhl wird nach Lage der Dinge noch zu den würmzeitlichen Terrassen zu zählen sein. Sie ist deutlich tiefer als eine höhere Terrasse in der Umgebung, auf der z.T. der Ort Obersuhl liegt. Die Schotter dieser höheren Terrasse sind westlich der Eisenbahn in einem großen Aufschluß untersucht worden. 
Nordwestlich Wanfried, nördlich und nordwestlich der Scheune und der Kläranlage westlich und östlich der Eisenbahn und der Bundesstraße 249 dehnen sich hier weite Terrassenflächen aus, die sanft $\left(\right.$ mit $\left.1-2^{\circ}\right)$ zur Werra abfallen und mit einem ca. $5 \mathrm{~m}$ hohen deutlichen Knick gegen den unteren Talboden („Untere Niederterrasse“) abbrechen. Die weite Terrassenfläche wird auch zur „Oberen Niederterrasse“, der 5- bis 8-m-Terrasse, gezählt. Bohrungen zeigten eine $80 \mathrm{~cm}$ mächtige Folge von hellem Sand $(10 \mathrm{~cm})$, sandigem Lehm mit Kalk- und Sandsteinen $(10 \mathrm{~cm})$, Lehm mit Kalk- und Sandsteinbrocken $(10 \mathrm{~cm})$, Lehm mit größeren, wenig gerundeten Sandsteinen $(20 \mathrm{~cm})$ und Lehm mit Sandsteinbrocken $(20 \mathrm{~cm})$, die am Top von einem $10 \mathrm{~cm}$ dicken lehmigen $A_{h}$-Horizont abgeschlossen wird. Ein „Werraschotterkörper“ wurde mit dem „Holländischen Sandbohrer“ nicht erreicht. Auch konnten hier als Decksedimente des Schwemmschuttes keine Lösse oder lößartigen Sedimente wie etwa bei Obersuhl gefunden werden. Die flächenhafte Entwicklung dieser 5- bis 8-m-Terrasse und ihr Aufbau lassen m.E. den Schluß zu, daß hier von NE von den Hängen her über kleine Nebentäler werrawärts herantransportierte Schwemmschuttmassen möglicherweise in einem älteren Talstadium, als die Werra 6-8 $\mathrm{m}$ höher als heute floß, von der Werra zumindest randlich überflossen und eingeebnet wurden. Diese Terrasse wird aufgrund ihrer Höhenlage und nach Analogieschlüssen (s.o.) in die Würmkaltzeit gestellt.

Die wichtigste Lokalität der 5- bis 8-m-Terrasse befindet sich am Gut Freudenthal nördlich von Ermschwerdt östlich der ehemaligen Limnologischen Flußstation, von MENSCHING (1953) als rißzeitliche Terrasse mit würmzeitlichem Solifluktionsschutt als Decksediment kartiert. Ein Aufschluß in dieser norphologisch deutlich hervortretenden Terrasse, deren Terrassenkante ca. 5-6 m über der Werra-Talaue liegt, befindet sich am Hang östlich der Limnologischen Station (R 35 5695, H 56922, Bl. 4724 Witzenhausen). MENSCHING (1953: 117) schreibt zum Unterschied zwischen rißzeitlicher Mittelterrasse und würmzeitlicher Niederterrasse: „Ein Unterschied in der Akkumulation der jüngsten Kaltzeit zu derjenigen der Rißeiszeit besteht jedoch darin, daß in der Würmeiszeit auf die Schotterablagerungen nicht allgemein eine mit Sand- und Lehmablagerungen folgt, wie es durch den Aufbau der Mittelterrasse für die Rißkaltzeit zum Ausdruck kam.“"

Der Aufschluß beim Gut Freudenthal und überdies ein weiterer Aufschluß bei Altenburschla (s.u.) scheinen diese Aussage nicht zu bestätigen. Bei Freudenthal (Abb. 3) reichen Werraschotter nur bis in Höhe der bei 130-131 m ü.N.N. liegenden Talaue (,Untere Niederterrasse") hinauf. Sie werden durch einen kleinen Bach am südöstlichen Rande angeschnitten und sind hier bis 1,0 bis $1,5 \mathrm{~m}$ unterhalb der Talauenoberfläche sichtbar. Die gleichen würmzeitlichen Schotter sind ca. $2 \mathrm{~km}$ weiter südöstlich bei Bischhausen (nordwestl. Witzenhausen) aufgeschlossen und hier infolge der zeitweiligen Abpumpung des Grundwassers in einer Mächtigkeit von 5 bis $6 \mathrm{~m}$ sichtbar. Die gesamte Schichtenfolge bei Freudenthal (Abb. 3) ist auf Tabelle 1 (nächste Seite) wiedergegeben.

Es kann sich bei den im Liegenden auftretenden Werraschottern nicht um rißzeitlichen Schotter der Hauptmittelterrasse (MENSCHING, 1953, Karte im Anhang) handeln; denn dieser Schotter soll nach MENSCHING (1953: 98) auf einem sich 3-6 m über der Talaue befindenden Felssockel liegen. Von der Höhenlage der Werraschotter im Liegenden ausgehend, stufe ich diese 5- bis 8-m-Terrasse mit ihren gut aufgeschlossenen Deckschichten als würmzeitliche Terrasse ein. Diese Datierung läßt sich einerseits durch weitere Beobachtungen an Ablagerungen in vergleichbarem Niveau und andererseits aufgrund der absoluten Höhen der Felssockel im Mittelterrassenbereich (Tab. 2) ${ }^{4}$ ) wahrscheinlich machen. Nach der Ab-

4) Die in Tabelle 2 dokumentierten Befunde wurden gemeinsam mit den Herren Priv.-Doz. Dr. H.-G. Molle, Berlin, und Universitätsrat Dr. G. Schulz, Berlin, gewonnen. 
Tab. 1: Sedimente bei Freudenthal (Abb. 3)

\begin{tabular}{|c|c|c|}
\hline $\begin{array}{l}\text { Schicht } \\
\text { Nr. }\end{array}$ & Mächtigkeit & Kennzeichnung des Materials \\
\hline 1 & $180 \mathrm{~cm}$ & $\begin{array}{l}\text { geschichteter Muschelkalk-Schwemmschutt mit dem Oberflä- } \\
\text { chenboden; }\end{array}$ \\
\hline 2 & $30-40 \mathrm{~cm}$ & $\begin{array}{l}\text { Sand mit einigen Geröllen (Thüringer Wald-Schotter), z.T. rin- } \\
\text { nenförmig in liegenden Hochflutlehm eingreifend; }\end{array}$ \\
\hline 3 & $40-50 \mathrm{~cm}$ & $\begin{array}{l}\text { braungelber, entkalkter Hochflutlehm (sehr dicht und fest), siehe } \\
\text { Abb. 3; }\end{array}$ \\
\hline 4 & $30 \mathrm{~cm}$ & $\begin{array}{l}\text { Schotter mit überwiegend Lokalmaterial und sehr wenig Werra- } \\
\text { material (weniger Werramaterial als im basalen Werraschotter), } \\
\text { kalkverbacken; }\end{array}$ \\
\hline 5 & $70 \mathrm{~cm}$ & $\begin{array}{l}\text { hellgrauer, z.T. weißer, z.T. rötlicher, geschichteter Sand mit } \\
\text { Linsen aus Werraschottern; }\end{array}$ \\
\hline 6 & $4-6 \mathrm{~m}$ & $\begin{array}{l}\text { Werraschotter mit viel Muschelkalk- und Buntsandsteinmaterial } \\
\text { und viel Thüringer Wald- und Rhönmaterial (nicht auf Abb. } 3 \text { zu } \\
\text { sehen). }\end{array}$ \\
\hline
\end{tabular}

lagerung des würmzeitlichen Niederterrassen-Schotterkörpers müssen zunächst Flußsande mit wenigen Geröllen abgelagert worden sein (wie übrigens auch im Anschluß an die Aufschotterung des Mittelterrassenschotterkörpers - siehe MENSCHING 1953: 117 und durch eigene, noch nicht veröffentlichte Ergebnisse zur Mittelterrasse belegt). Als die Werra danach begann, sich erstmals auf ganzer Breite einzutiefen, kam es in einer Phase, als offenbar noch Löß abgelagert wurde, zu einer innerwürmzeitlichen Hochflutablagerung, die wahrscheinlich noch innerwürmzeitlich pedogenetisch überprägt wurde. Als würmzeitlich, möglicherweise u.a. auch spätglazial, werden die hangenden, z.T. geschichteten Muschelkalk-Schwemmschutte eingestuft, die ihren Ursprung in den direkt angrenzenden Muschelkalkhängen haben.

Die Werra-Niederterrassenschotter nordwestlich Bischhausen bei Witzenhausen werden in einem nahe der Bundesstraße 8 gelegenen Aufschluß gleichfalls von Muschelkalkschwemmschuttmassen und holozänem Bodenkolluvium bedeckt. Offenbar läßt sich die Überlagerung von Werraschottern durch jüngere Schwemmschuttsedimente, die MENSCHING (1953: 117) für die Werra-Mittelterrassen herausstellt, auch bei dem würmzeitlichen Niederterrassenschotterkörper feststellen.

Bei den bisherigen Ausführungen zum Werra-Niederterrassenkomplex war in erster Linie die Höhenlage des Schotterkörpers, von $6 \mathrm{~m}$ unter der Talaue bis ca. 2-5 m über der Taulaue, ausschlaggebend für seine Einstufung in die Würmkaltzeit. Südlich der Burg Ludwigstein (im Talabschnitt Werleshausen-Oberrieden) war 1976 bei Straßenbauarbeiten ein ca. 1,3 m mächtiger gelbbrauner Löß mit Naßbleichungserscheinmungen ${ }^{5}$ ) über Schwemmschuttmassen aufgeschlossen, die aus dem Trockentälchen südlich des Ludwigsteins bzw. aus dem Rodenbach stammen. Der Löß befindet sich hier 3-4 $\mathrm{m}$ über der Werratalaue und unterscheidet sich von dem Auelehm durch seine lockere Struktur, seine gelbe Farbe und Naßbleichung. Anzeichen für eine fossile Bodenbildung in dem Löß konnten

5) Ähnliche Lösse auf der Niederterrasse sind mir später auch im südlichen Wesertal bei der Kiesgrube Ochsenhof (gegenüber dem Kloster Bursfelde) und anläßlich mehrerer von Herrn Prof. Dr. B. MEYER geführter Exkursionen im Leinetal nahe dem Autobahnzubringer Northeim-Nord (bei Edesheim) bekannt geworden. 
nicht gefunden werden. - Bei Altenburschla (südl. Wanfried) konnte in einer NTSchottergrube nahe der Grenze zur DDR gelber Löß in ein bis drei dünnen Bändern zwischen Schotterkörper und Auelehm gefunden werden.

Zum Vergleich kann der Schwemmfächer des Höllentales (Berkatal) bei Albungen herangezogen werden, der im Jahre 1976 über mehrere Monate während der Straßenbauarbeiten aufgeschlossen war (Abb. 4). Dieser Schwemmfächer wird heute von der Berka 3-5 m

$N \boldsymbol{W}$

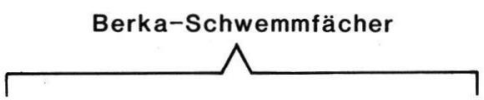

$S E$

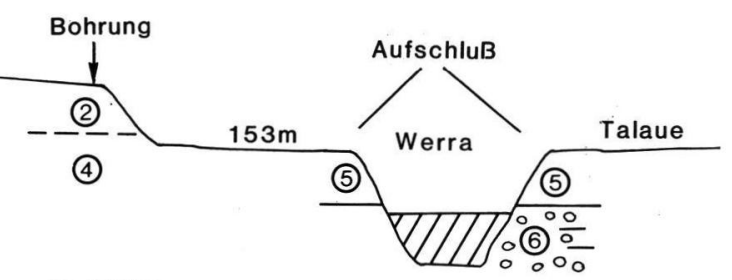

ca $150 \mathrm{~m}$

Abb. 4: Der Berka-Schwemmfächer (Höllental) bei Albungen $1=$ Löß mit Parabraunerde; 2 = primärer, gelber Löß; 3 = Rostfleckiger Löß (Naßboden?); 4 = Schwemmschutt aus Albunger Paläozoikum; $5=$ Auelehm; $6=$ Niederterrassenschotter der Werra.

tief zerschnitten. Er endet mit einem ca. $2 \mathrm{~m}$ hohen, scharfen Knick oberhalb der bei ca. $153 \mathrm{~m}$ ü.M. liegenden Werra-Talaue südlich der Lokalität Heiligenstein, wurde also, nachdem die Schwemmschuttanlieferung aus dem Höllental aufgehört hatte, von der sich eintiefenden Werra unterschnitten. - Das Schwemmschuttmaterial besteht aus Albunger Paläozoikum, aus Buntsandstein, Muschelkalk und aus Basalt des Meißners. Der auf dem Schwemmschuttfächer liegende, z.T. 2-2,5 m mächtige Löß ist von einer erodierten holozänen Parabraunerde mit einem $\mathrm{B}_{\mathrm{t}}$ - und einem $\mathrm{C}_{\mathrm{Ca}}$-Horizont bedeckt, ist als echter gelber Primärlöß entwickelt und weist unterhalb des $\mathrm{C}_{\mathrm{Ca}}$-Horizontes eine Rostfleckenzone auf. Möglicherweise handelt es sich hierbei um den jüngsten Jungwürm-Naßboden. Unter diesem folgt hier noch 0,5 m primärer Rohlöß. Im Prinzip liegen hier also Verhältnisse vor, wie sie SEMMEL (1972a: 109) in der Ziegeleigrube Wölfershausen in einem westlichen Nebental der Werra ebenfalls fand. Allerdings stuft SEMMEL (1972a: 109) den von ihm gefundenen Naßboden als möglichen $\mathrm{E}_{2}-\mathrm{Naßboden}$ ein.

Folgende Schlüsse für das Werratal-Geschehen lassen sich aus den Befunden im Höllental-Schwemmkegel bei Albungen ableiten (Abb. 4): Der Schwemmfächer der Berka wurde in einer Phase starker Verwitterung und Schuttverlagerung auf einen Werratalboden geschüttet, der deutlich höher lag als die heutige Grenze Auelehm/Werraschotter. Er war damit auf ein Niveau eingestellt, bis zu dem im Aufschluß Freudenthal und in Kiesgruben bei Eschwege reine Werraschotter abgelagert worden sind. Die heutigen Relief- und Sedimentlagerungsverhältnisse am Berkatalschwemmfächer bei Albungen lassen auf eine nach Ablagerung des Schwemmschuttes erfolgte Werra-Eintiefung schließen, die wenigstens $3 \mathrm{~m}$ betragen hat. Es wird für wahrscheinlich gehalten, daß diese Eintiefung im Spätglazial, und zwar vor der Allerödzeit, erfolgt ist; denn zu dieser Zeit wurden z.B. bei Eschwege nachweislich Rinnen in den würmzeitlichen Schotterkörper eingetieft (vgl. Kap. 3.4.). Theore- 
Tab. 2: Höhenangaben zur Werra-Talaue, zur Sockelhöhe und Akkumulationshöhe möglicher rißzeitlicher Terrassen im Talabschnitt zwischen Bad Sooden-Allendorf und Philippsthal

\begin{tabular}{|c|c|c|c|c|c|c|}
\hline Aufschluß & $\begin{array}{c}\text { I } \\
\text { Werra-Tal- } \\
\text { aue }\end{array}$ & $\begin{array}{l}\text { II } \\
\text { Felssockel- } \\
\text { höhe }\end{array}$ & $\begin{array}{l}\text { III } \\
\text { Differenz } \\
\text { I u. II }\end{array}$ & $\begin{array}{c}\text { IV } \\
\text { Akkumula- } \\
\text { tionshöhe }\end{array}$ & $\begin{array}{c}\mathrm{V} \\
\text { Differenz } \\
\text { IV u. II }\end{array}$ & $\begin{array}{l}\text { VI } \\
\text { Akk.-Art }\end{array}$ \\
\hline $\begin{array}{l}\text { Bad Sooden- } \\
\text { Allendorf }\end{array}$ & $\begin{array}{l}149 \mathrm{~m} \\
\text { ü. NN }\end{array}$ & 173,37 & 24,37 & 177,87 & 4,50 & $\begin{array}{l}\text { Werra-Sch. } \\
\text { unt. Schwemm- } \\
\text { Schutt }\end{array}$ \\
\hline Albungen & 153,50 & $\begin{array}{l}182,82 \\
173,06\end{array}$ & $\begin{array}{l}29,32 \\
19,56\end{array}$ & $\begin{array}{l}185,67 \\
175,66\end{array}$ & $\begin{array}{l}2,85 \\
2,60\end{array}$ & $\begin{array}{l}\text { Werra- } \\
\text { Schotter }\end{array}$ \\
\hline $\begin{array}{l}\text { Niederhone } \\
\text { (unsicher, da Sockel }\end{array}$ & $\begin{array}{r}156,10 \\
\text { I geneigt) }\end{array}$ & $178,18 ?$ & $22,08 ?$ & $185,08 ?$ & 6,90 & \\
\hline Jestädt & 157,0 & - & - & ca. 165,0 & ca. 8,0 & $\begin{array}{l}\text { Schwemm- } \\
\text { schutt }\end{array}$ \\
\hline Grebendorf & 158,0 & 172,08 & 14,08 & 177,38 & 5,30 & $\begin{array}{l}\text { Werra-Sch. } \\
\text { u. Sand unter } \\
\text { mächtigem } \\
\text { Schwemmsch. }\end{array}$ \\
\hline Völkershausen & 167,50 & 186,68 & 19,18 & 190,58 & 3,90 & $\begin{array}{l}\text { Werra- } \\
\text { schotter }\end{array}$ \\
\hline $\begin{array}{l}\text { Altenburschla } \\
\text { (Schreiber) }\end{array}$ & 170,0 & 166,55 & $(-) 3.45$ & 197,40 & 30,85 & $\begin{array}{l}\text { Werra-Kies } \\
\text { u. Sand }\end{array}$ \\
\hline Heldra & 170,50 & 185,09 & 14,59 & 194,96 & 9,87 & $\begin{array}{l}\text { Werra-Sch. } \\
\text { unter } \\
\text { Schwemmsch. }\end{array}$ \\
\hline Herleshausen & 199,0 & $\begin{array}{l}201,07 \\
210,64\end{array}$ & $\begin{array}{r}2,07 \\
11,64\end{array}$ & & & Schotterstreu \\
\hline $\begin{array}{l}\text { Herleshausen/ } \\
\text { Wommen }\end{array}$ & 201,0 & unter 209,80 & - & 216,47 & - & $\begin{array}{l}\text { Werra- } \\
\text { Schotter }\end{array}$ \\
\hline Wommen & 202,0 & 211,76 & 9,76 & 218,33 & 6,57 & $\begin{array}{l}\text { Werra-Sch. } \\
\text { unter Lokalsch. }\end{array}$ \\
\hline Obersuhl & 210,0 & 226,15 & 16,15 & 242,0 & 15,85 & $\begin{array}{l}\text { Werra- } \\
\text { Schotter }\end{array}$ \\
\hline Kleinensee & 211-212 & ca. 230 & ca.18-19 & $233-234$ & $3-4$ & $\begin{array}{l}\text { Lokal- } \\
\text { Schotter }\end{array}$ \\
\hline Wölfershausen & 215,50 & 242,13 & 26,63 & 248,85 & 6,72 & $\begin{array}{l}\text { Lokal-Schotter } \\
\text { unter Rißlöß }\end{array}$ \\
\hline \multicolumn{7}{|l|}{ Unteres Werratal } \\
\hline $\begin{array}{l}\text { Witzenhausen } \\
\text { (n. Mensching } \\
\text { 1953) }\end{array}$ & $134-135$ & 150,0 & 15,0 & 155,0 & 5,0 & Schotter \\
\hline $\begin{array}{l}\text { Unterrieden } \\
\text { (n. Garleff 1966) }\end{array}$ & $135-138$ & ca. $-1,0$ & & $147-155$ & $12-20$ & $\begin{array}{l}\text { Schotter, } \\
\text { Sand u. Schutt }\end{array}$ \\
\hline
\end{tabular}

tisch ist allerdings auch eine spätere Eintiefung der Werra möglich gewesen. Während der Eintiefungsphase konnte, sofern sie noch ins Spätglazial fiel, auf dem Schwemmfächer primärer Löß abgelagert werden. Beachtet man die mögliche jungwürmzeitliche schwache Bodenbildung in dem gelben Löß, so läßt sich das Alter des Schwemmschuttes als sicher würmzeitlich einstufen. Darauf weist auch bereits der gelbe Primärlöß auf dem Schwemmfächer hin. Die Ablagerung des 2,5 m mächtigen Lösses auf dem Schwemmfächer wurde aber erst möglich, als der Schwemmfächer nicht mehr von der Berka überflossen wurde, 
d.h. als die Berka begann, sich in den eigenen Schwemmfächer einzutiefen. Das kann wiederum erst erfolgt sein, als der Vorfluter, die Werra, ebenfalls begann, sich einzuschneiden. So läßt sich also über die Analyse des Schwemmfächeraufbaus bei Albungen die Eintiefung der Werra ins obere Jungwürm bis ins Spätglazial einstufen, wobei nicht ganz geklärt ist, wann dies im Jungwürm genau geschah.

Die Befunde lassen den indirekten Schluß zu, daß auch die Werraschotter an anderen Lokalitäten, die heute ca. $3 \mathrm{~m}$ über der Werratalaue liegen, in der Würmkaltzeit akkumuliert wurden und die Werra im Laufe des jüngeren Jungwürm bereits sich einzutiefen begann. Es sei daran erinnert, daß die bei Freudenthal über dem Werraschotter liegenden Hochflutlehme bereits einen ähnlichen Schluß nahelegten (s.o.); denn hätte sich hier die Werra nicht nach Ablagerung der Werraschotter wieder eingetieft, so hätte es hier nicht zur Ablagerung von (lößbürtigen?) Hochflutsedimenten kommen können. In Freudenthal muß allerdings im Gegensatz zu der Lokalität Berka-Schwemmfächer bei Albungen im Zuge der weiteren Eintiefung der Werra die morphodynamische Aktivität auf den benachbarten $\mathrm{Mu}$ schelkalkhängen kräftig eingesetzt haben, wie die Muschelkalk-Schwemmschuttmassen über dem Hochflutlehm bezeugen (Abb. 3). Zeitlich ist diese Phase m.E. auch in das obere Jungwürm, vielleicht auch noch z.T. in das Spätglazial zu stellen.

In diesem Zusammenhang ist nochmals auf den Aufschluß bei Obersuhl zurückzukommen, wo die 5- bis 8-m-Terrasse mit 0,5-1,0 m mächtigem braungelbem, sandigem Deckschluff bedeckt ist. Auch hier muß die Werraschotter-Akkumulation zu einem Zeitpunkt abgeschlossen gewesen sein, als noch schluffig-sandiges (lößbürtiges) Material zur Verfügung stand, das weite Terrassenflächen bedeckte. Das könnte am ehesten auch im oberen Jungwürm, vielleicht auch noch z.T. im Spätglazial der Fall gewesen sein, denn die liegenden Niederterrassenschotter sind hier wahrscheinlich noch durch frostdynamische Aktivität in das feine Decksediment aufgefroren (s.o.).

Abschließend sei hervorgehoben, daß sich für den Nachweis von zwei echten Werraschotterkörpern, die ineinandergeschachtelt wurden, d.h. jeweils nach einer Phase der Tiefenerosion aufgeschüttet wurden, bisher keine Anhaltspunkte ergaben. Nach den Ausführungen und der Abb. 3 von Semmel (1972a: 109) sowie nach der die Terrassen zusammenfassenden Abb. 2 bei ELLENBERG (1968a) kann allerdings der Eindruck entstehen, als seien zwei würmzeitliche Werraschotterkörper für den mittleren Werraabschnitt nachweisbar. Ein persönliches Gespräch mit Herrn Prof. Dr. A. SEMmEL, Frankfurt, ergab jedoch, daß sich seine Ausführungen und seine Abb. 3 zur mittleren Werra bei Wölfershausen (Abb. 3 bei SEMMEL 1972a) nur auf das westliche Nebental der Werra bei Wölfershausen beziehen, in dem in der ehemaligen Ziegeleigrube von Wölfershausen die Aufschlußverhältnisse untersucht wurden.

ELlenberg (1968a: 679) stellt die „Obere Niederterrasse“, die Terrasse mit 1-2 m relativer Höhe, die er in der Abb. 2 noch in die Würmkaltzeit stellt, in einer Fußnote (S. 679) in den Saale-Komplex. Es ist mir z.Z. unmöglich, diese Umdatierung zu beurteilen.

\section{Die spätglaziale und holozäne Überformung des Werratalbodens}

\subsection{Einleitung}

An der oberen und mittleren Werra tritt zwischen dem Auelehm und dem Niederterrassen-Schotterkörper ein typisches Sediment auf, das UNGER (1963, zit. n. ELLENBERG 
1968 a: 673$)^{6}$ ) an der Werra als „Ried“ bezeichnet hat. Es handelt sich dabei entweder um humosen, blaugrauen, fetten Ton, der meist mit Pflanzenresten und Vivianitknollen durchsetzt ist. Oder der Ried tritt in der faziellen Ausbildung eines vorwiegend grauen, siltigen Fein- und Mittelsandes auf, der ebenfalls Pflanzenreste und vereinzelt Vivianit enthält und über den Stellen größter Absenkung des Untergrundes auftreten soll (ELLENBERG \& KUHN 1967: 74). Nach UNGER (1963), ELLENBERG (1968 a: 673 f.) und ELLENBERG \& KUHN (1967: 74) handelt es sich dabei um ein holozänes Sediment, das zwischen 1 und $3 \mathrm{~m}$ dick ist; es unterscheidet sich deutlich vom Auelehm bzw. Auesand.

\subsection{Der „Ried“ bei Eschwege und Schwebda}

In der südöstlich des Dreiecks der Straßen Grebendorf - Eschwege und Schwebda Eschwege gelegenen Grube (Abb. 1, 2 u. 5) war in den Jahren 1973 und 1974 neben dem

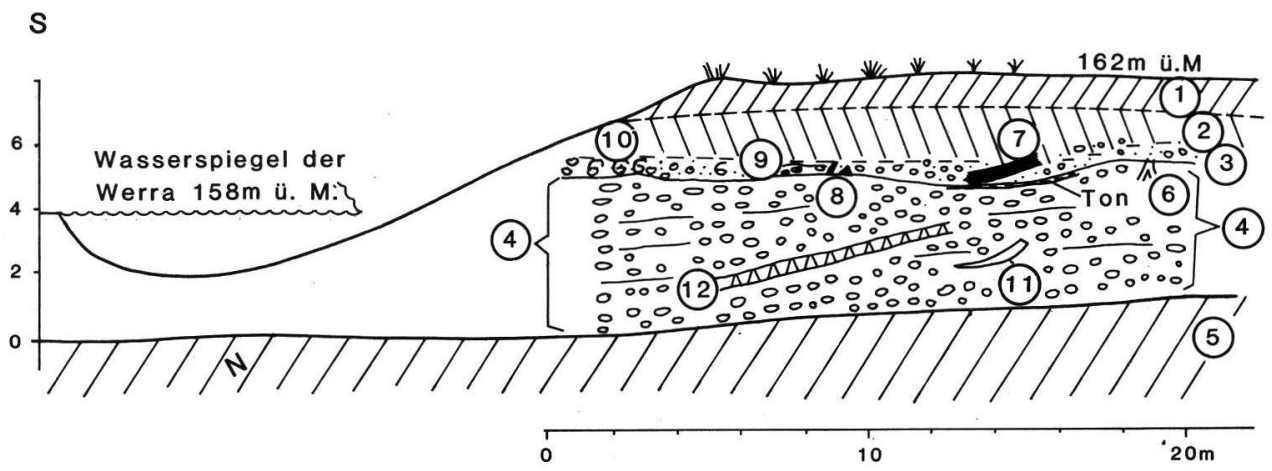

Abb. 5: Auelehm, Ried und Niederterrasse südöstlich der Einmündung der Straße Schwebda Eschwege in die Straße Grebendorf - Eschwege; linker Teil generalisiert.

1 = Oberer Auelehm; 2 = Unterer Auelehm; 3 = Ried-Formation: fetter Ton, lehmiger Sand, Sand, Kies, Torf, z.T. in flache Rinnen eingelagert, kaum geschichtet; $4=$ Niederterrassen-Schotterkörper mit Eichenstämmen und Mammut-Stoßzahn; 5 = Buntsandstein-Felssockel; 6 = Baumstubben aus morschem Holz; 7 = Umgefallener Baumstamm in Rinne; 8 = Holzkohle; 9 = Torf und morsche Äste; 10 = Schnecken und Flußmuscheln; 11 = Mammut-Stoßzahn, angeblich in dieser Aufschüttung gefunden; 12 = Eichenbaumstämme, angeblich in dieser Aufschüttung gefunden.

Oberen und dem Unteren Auelehm (Abb. 5) der „Ried“ (3) und der NiederterrassenSchotterkörper (4) aufgeschlossen. Der Untere Auelehm (2), der der Schicht 6 in Abb. 6 und 7 entspricht (s.u.), wies hier nicht die Auen-Schwarzerde auf, die 1976 bis 1979 im benachbarten Aufschluß nördlich der Straße Schwebda-Eschwege häufiger gefunden wurde.

Beachtung verdient in diesem Aufschluß vor allem der „Ried“, bei dem es sich wahrscheinlich um den „Oberen Ried“ meiner in Kapitel 3.4. ausgeschiedenen und begründeten „Ried“ablagerungen handelt. Er ist als heller, schlecht geschichteter Sand, Kies, fetter, blaugrauer Ton, toniger Sand, z.T. auch als Torf entwickelt und, wie Abb. 5 zeigt, z.T. in flache Rinnen eingelagert. Im Jahre 1973 waren zeitweilig Baumstubben (6) zu beobachten, die am

6) Bei diesem Zitat bezieht sich ELLENBERG (1968a: 673) auf eine unveröffentlichte Arbeit von UNGER (1963): „Erläuterungen zur geologischen Karte der DDR 1: 25000 , Meßtischblatt Weißensee (Nr. 4732). - Ber. VEB Geol. Erkundung. Halle, BA Jena, Jena 1963“. 


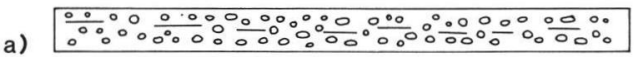

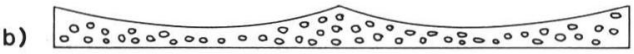

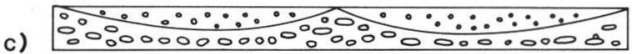

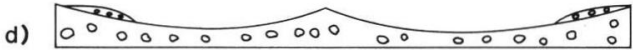

e)

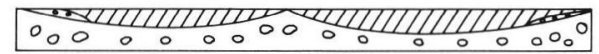

f)

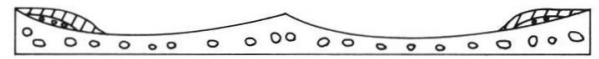

g)

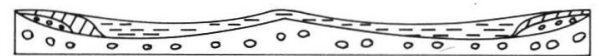

h)

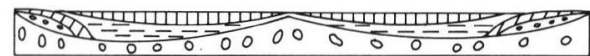

i)
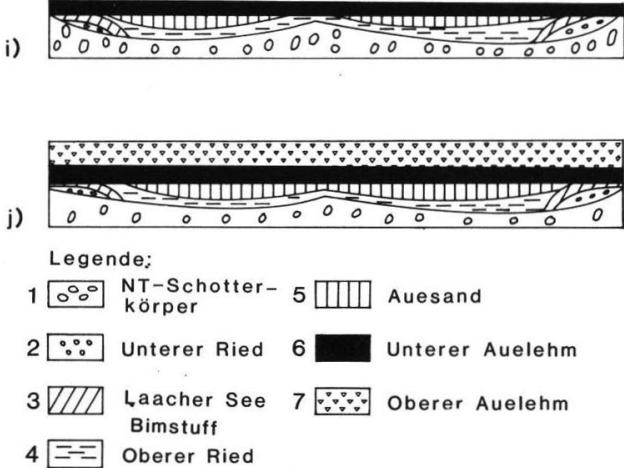

Abb. 6: Spätglaziale Rinnenbildung im Werratal nördlich Eschwege Lokalität wie bei Abb. 7. Aufnahme im Jahre 1977.

Rande einer 0,5-0,7 m tiefen „Ried“-Rinne vom „Ried“ aus in den NiederterrassenSchotterkörper hinabreichten. Es muß sich bei den Bäumen am ehesten um Reste eines Auewaldes am Rande von flachen Rinnen handeln. Ein in der Rinne liegender Baumstamm (7), der anläßlich der Kasseler Geographentag-Exkursion 1973 gefunden wurde, ist als abgestorbener oder seitlich unterschnittener Auebaum aufzufassen. In hellem Sand des „Ried“ gefundene Holzkohle, Torf und verfaulte Äste (9) konnten noch nicht näher untersucht 


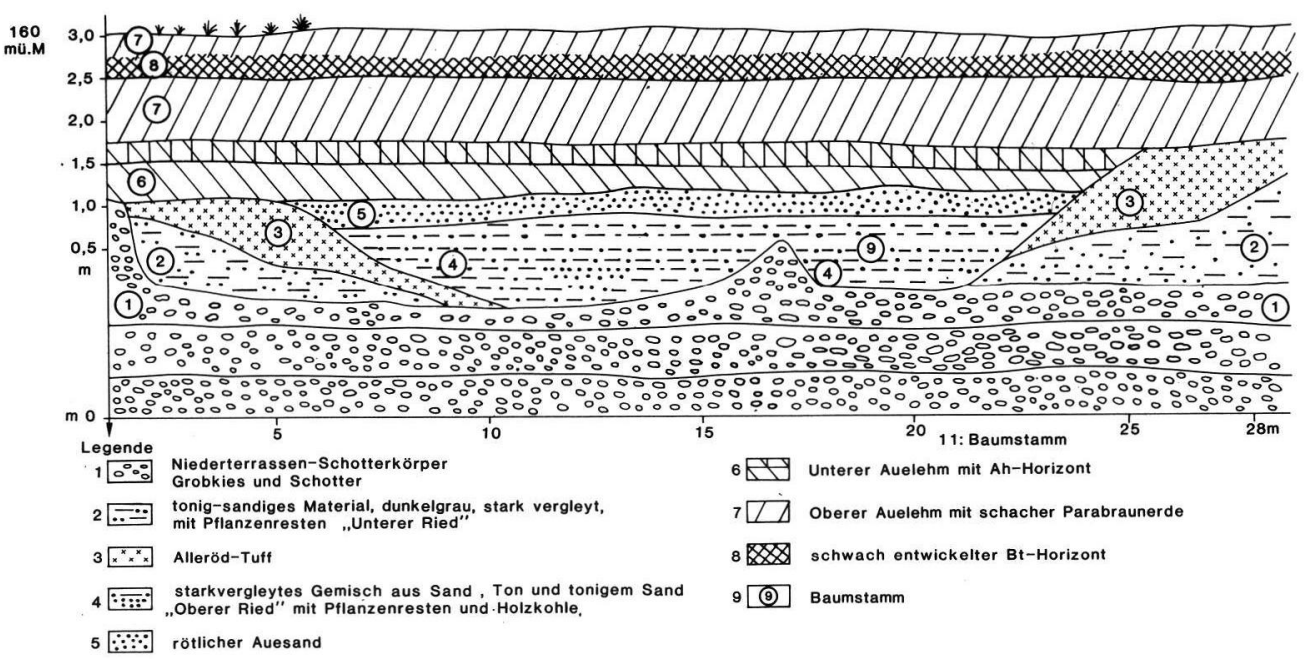

Abb. 7: Spätglaziale Rinnen im Werratal bei Eschwege ca. $300 \mathrm{~m}$ östlich der Straßeneinmündung der Straße Schwebda-Eschwege in die Straße Eschwege-Grebendorf. Aufnahme im Sommer 1977.

werden. Besondere Aufmerksamkeit verdienen die von mir im Jahre 1973 gesammelten und dankenswerterweise von Herrn Dr. Schütt, Düsseldorf, bestimmten und z.T. interpretierten Flußschnecken- und Flußmuschelschalen, die sonst relativ selten auftreten.

Es kamen vor: Wasserkiemenschnecken, Wasserlungenschnecken, Landlungenschnecken und Flußmuscheln. Die Faunenliste lautet (Tab. 3):

Tab. 3: Faunenliste der Schnecken und Muscheln aus dem „Ried“ bei Eschwege (Grube südöstl. d. Straßendreiecks der Straßen Eschwege-Schwebda und Grebendorf-Eschwege)

Stückzahl

\begin{tabular}{|c|c|c|}
\hline $\begin{array}{l}\text { ca. } \begin{array}{l}7 \\
1 \\
1 \\
\text { juv. }\end{array} \\
\text { ca. } 10\end{array}$ & $\begin{array}{l}\text { Valvata piscinalis (O. F. MÜLLER 1974) } \\
\text { Valvata pulchella (STUDER 1790) } \\
\text { Viviparus viviparus (LINNAEUS 1758) } \\
\text { Bithymia tentaculata (LINNAEUS 1758) }\end{array}$ & $\begin{array}{l}\text { Wasserkiemen- } \\
\text { schnecken }\end{array}$ \\
\hline $\begin{array}{r}30 \\
1 \\
2 \\
\text { ca. } 10\end{array}$ & $\begin{array}{l}\text { Radix ovata (DRAPARNAUD 1805) } \\
\text { Anisus septemgyratus (E. A. BIELITZ 1863) } \\
\text { Gyraulus albus ROSSMÄSSLER } \\
\text { Ancylus fluviatilis (O. F. MÜLLER 1774) }\end{array}$ & $\begin{array}{l}\text { Wasserlungen- } \\
\text { schnecken }\end{array}$ \\
\hline $\begin{array}{l}1 \\
1 \\
1 \\
1\end{array}$ & $\begin{array}{l}\text { Pupilla muscorum (LINNAEUS 1758) } \\
\text { Vallonia costata (O. F. MÜLLER 1774) } \\
\text { Retinella nitens (MICHAUD 1831) } \\
\text { Cepaea bortensis (O. F. MÜLLER 1774) }\end{array}$ & $\begin{array}{l}\text { Landlungen- } \\
\text { schnecken }\end{array}$ \\
\hline
\end{tabular}


Stückzahl

$\left.\begin{array}{rl}\hline \text { ca. } 30 & \text { Unio crassus batavus (MATON \& RACKET 1807) } \\ 2 & \text { Pisidium amnicum (O. F. MÜLLER 1774) } \\ 1 & \text { Pisidium supinum (A. SCHMIDT 1850) } \\ 1 & \text { Pisidium henslowanum (SHEPPARD 1823) }\end{array}\right\} \quad$ Muscheln

Ganz ähnliche „Ried“sedimente unter zwei verschiedenen Auelehmen findet man auch im benachbarten Leinetal (z.B. beim Reinshof nördl. Niedernjesa), wo sie mir anläßlich einer Exkursion auf dem 42. Geographentag in Göttingen (Führung Prof. Dr. B. Meyer, Göttingen) bekannt wurden. Verschiedene Details wie Flußmuscheln und -schnecken, Holzreste, Mudden und Baumstubben treten in dem Leineabschnitt zwischen Friedland und Northeim auf. Der untere (nicht so kräftig rotbraun gefärbte) Auelehm, der hier aus spätglazialem Löß oder Lehm hervorgegangen ist, trägt im Leinetal - wie an manchen Stellen im Werratal - eine Auen-Schwarzerde bzw. ist durch hohe Anteile von humosem Material gekennzeichnet.

Aus dem Schreiben von Herrn Dr. H. Schütt, Düsseldorf, vom 25. 9. 1973: „Die große Muschelart ist einheitlich nur Unio crassus batavus. Es sind aber noch drei Arten der Muschelgattung Pisidium darunter, in jeweils nur einem Stück (bei amnicum 2).“ „Faunistisch handelt es sich um typische Flußbewohner. Alle vier Muschelarten und die meisten Schnecken kommen oder kamen auch im Rhein vor. Die große Muschel Unio crassus ist über Europa in mehreren geographischen Rassen verbreitet, von denen die Rasse batavus MORTON \& RACKET das Einzugsgebiet des Rheines besucht. Zu dieser Rasse gehört auch Ihr Material. Es sind auch vier Landschneckenarten in Ihrer Ausbeute enthalten, die ins Wasser gefallen sind oder dem Genist entstammen. Sie sind zoogeographisch oder faunistisch nicht interessant. Allerdings sind es Arten, die auch in Lößfaunen häufig vorkommen. Interessant ist die Wasserlungenschnecke Anisus septemgyratus E. A. BIELTZ. Sie deutet auf älteres Quartär hin. Sie ist beispielsweise in den Quartärsanden von Wiesbaden-Biebrich ziemlich häufig."

Die zeitliche Einstufung und Deutung bereitet z.Z. noch einige Schwierigkeiten ${ }^{7 a}$ ), zumal das in der Rinne liegende muddeartige Material noch nicht pollenanalytisch untersucht wurde. Mit einiger Sicherheit läßt sich sagen, daß nach der weitflächigen Sedimentation der Niederterrassen-Schotter, die nach Kap. 2.2. etwa im oberen Jungwürm (nach den Zeitbezeichnungen der Lößstratigraphie), vielleicht auch erst zu Beginn des Spätglazials, beendet war, flächenhafte fluviale Überformung des Werrabodens und schwache Erosion (Rinnenbildung) begann. Wann diese Umstellung genau erfolgt ist, ist z.Z. noch nicht klar. Es kann sich hierbei eventuell um einen recht jungen holozänen Vorgang handeln, der noch vor die auch von mir nicht genau datierte Bildung der flächenhaft entwickelten 1,5-2,0 m mächtigen Auelehme zu stellen ist: Nimmt man nämlich an, daß die Entstehung der Oxydationsbänder im oberen Teil des Niederterrassen-Schotterkörpers durch einen schwankenden Grundwasserstand nach Beseitigung des eiszeitlichen Dauerfrostbodens erfolgt ist - woran m.E. kein Zweifel besteht -, so kann die zur Rinnenbildung führende Erosion, die ja diese Oxydationsbänder kappte, erst deutlich nach der Ausbildung eines Grundwasserkörpers geschehen sein. Dieser Umstand spricht m.E. für einen holozänen Rinnenbildungsprozeß, es sei denn, man stellt die erste Bildung eines Grundwasserkörpers in das Böllig- und/oder Alleröd-Interstadial.

Nicht auszuschließen ist allerdings, daß in dem Phänomen der Schotterrinnen im Werratal ein Pendant zu der von KOZARSKI $\left.(1977)^{7}\right)$ und KOZARSKI \& ROTNICKI (1977) beschriebenen Verwilderung des Flußnetzes von Warthe und Bug vorliegt. In Nordpolen zeichnet sich das Phänomen der Verwilderung des Flußnetzes nicht durch große Mäanderbogen aus,

7) Vortrag im Berliner Geographischen Kolloquium im Oktober 1977.

7a) Diese Aussage bezieht sich nur auf die Aufschlußverhältnisse von Abb. 5. 
die zwei verschiedenen jüngeren Flußgenerationen angehören, sondern durch eine Schrägund Kreuzschichtung der Schotterkörper, die im Bölling-Interstadial aufgehört hat. In dem Dominieren der Schräg- und Kreuzschichtung gegenüber der normalen horizontalen Schichtung im Hochwürm-Schotterkörper liegt nach KOZARSKI \& ROTNICKI (1977) der Hauptunterschied zu dieser älteren Art der Sedimentation. Betrachtet man die Abb. 2 dieser Arbeit, so erkennt man auch hier eine deutliche Schrägschichtung. KOZARSKI \& ROTNICKI (1977) führen als Gründe für die spätglaziale Verwilderung des Flußnetzes die Degradation des Permafrostes und die dadurch bedingte Veränderung des Abflußgeschehens an; außerdem wird zu dieser Zeit mit einer Ausbreitung der Pflanzendecke und mit einer größeren Verdunstung gerechnet.

\section{3 Ältere Schotterumlagerungen und Schotterrinnen über dem Werra-Niederterrassenkörper}

Die Abbildungen 1 und 2 lassen erkennen, daß sich in den gut geschichteten, $4-5 \mathrm{~m}$ mächtigen Niederterrassen-Schotterkörper auf einer Breite von ca. 10 Metern Rinnen eingetieft haben, die mit Schottern gefüllt sind. Diese Rinnen erreichen eine Tiefe von 1,0-1,5 m, an einer Stelle (nördl. der Lokalität von Abb. 1 u. 2) von 2 m. Hervorgehoben sei, daß es sich dabei um keine ubiquitären Erscheinungen handelt, sondern daß sie bisher erst in zwei benachbarten Gruben im Werratal nördl. Eschwege angetroffen worden sind ${ }^{8}$ ).

Die Schotter in den Rinnen (in Abb. 1 ist rechts der Mitte des Bildes ein Teil einer solchen Schotterrinne sichtbar) unterscheiden sich von den liegenden Niederterrassenschottern dadurch, daß sie kaum bzw. viel schlechter als diese geschichtet sind. Sie sind schmutzig-grau. Die durch kräftige farbliche Markierung gekennzeichneten Schotterbänder (Eisen-Oxydationsbänder und Manganbänder) im eigentlichen NiederterrassenSchotterkörper setzen an den Rinnen aus. Meistens sind auch die Schotter in den Rinnen feinkörniger. Die „Rinnenschotter“ setzen sich z.T. in Mächtigkeiten von ca. 0,5 m (Abb. 2, linker Teil) auf die liegenden, gröberen Niederterrassenschotter fort. In einem Falle (Abb.2, rechts der Mitte) befand sich am Grunde einer Rinne ein mudderartiges, humoses Feinmaterialband, das aber bisher noch nicht untersucht wurde. Ob zwischen dem „Rinnenschotter" und dem 1,5-2 m mächtigen häufig zweigeteilten Auelehm noch Sedimente des „Ried“ vorkommen, kann noch nicht gesagt werden, denn an den entscheidenden Stellen (Abb. 1 und 2) war das direkt auf den „,Rinnenschottern“ liegende Sediment bereits künstlich abgetragen worden.

\subsection{Die spätglaziale Überformung des Werratalbodens durch Rinnen}

Die spätglaziale Überformung des Niederterrassen-Schotterkörpers ließ sich seit 1974, als von mir der Laacher Bimstuff auch in großen Mächtigkeiten in Rinnen auf dem Schotterkörper gefunden wurde (Abb. 8 und 9), wiederholt recht genau studieren. Es wurden Aufschlüsse südwestlich von Schwebda (nahe dem westlichen Ortsschild von Schwebda), westlich von Schwebda (in einem 4-5 m tiefen, zeitweilig zugänglichen, künstlich ausgehobenen Graben, der für den Bau der Abwasserleitung von Schwebda nach Grebendorf

8) Zumindest Schotterumlagerungen, z.T. auch in Rinnen, hat es auch auf dem NiederterrassenSchotterkörper der Leine gegeben (HUGENROTH \& MEYER 1979): Exkursionsmaterial „Auenprofil Northeim-Nord" und Prof. Dr. B. Meyers mündliche Erläuterungen anläßlich der Exkursion 21 auf dem Göttinger Geographentag 1979. 


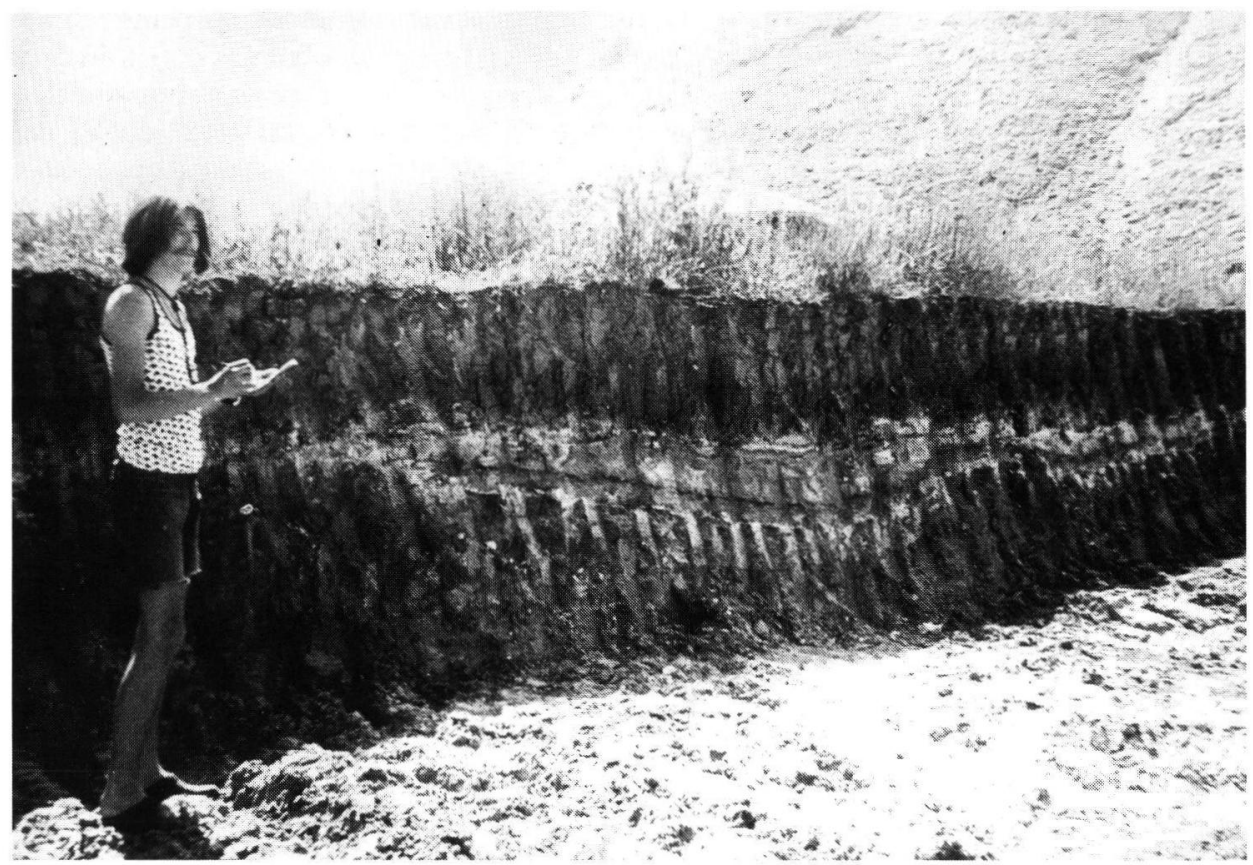

Abb. 8: Laacher See-Bimstuff-Mischsediment in zwei flachen Rinnen bei Eschwege (gleiche Lokalität wie bei Abb. 1 und 2). Schichtung im Tuff-Mischsediment schwach erkennbar. Hangender Auelehm mit Bt-Horizont (dunkel). Unter dem Tuff-Mischsediment sandig-kiesige Sedimente, die in Niederterrassen-Schotterkörper (helle Fläche im Vordergrund) übergehen. Aufnahme Brosche, Sommer 1977.

in einer alten Werratiefenlinie ausgehoben wurde), und vor allem nördlich Eschwege (nördlich der Straße Eschwege - Schwebda, ca. 300 m östlich des Straßendreiecks der Straßen Eschwege - Grebendorf und Eschwege - Schwebda) z.T. mehrfach aufgenommen. Stellvertretend für die anderen Aufschlüsse seien hier nur die zuletzt genannte große Grube der Werra-Kies- $A G^{9}$ ) beschrieben und interpretiert (Abb. 6 und 7).

Der Aufschluß war zwischen 1975 und 1979 der einzige, der aufgrund der mehrfach erwähnten Abpumpung des Grundwassers ein lückenloses Profil vom Buntsandstein-Felssockel unter dem Niederterrassen-Schotterkörper bis zur Oberfläche des Auelehms bot. Diese liegt bei ca. $160 \mathrm{~m}$ ü.M.

An der Ostwand haben sich in den gut geschichteten Werra-Niederterrassenkörper zwei Rinnen von je ca. 15 m Breite direkt nebeneinander eingetrieft. Sie sind mit Material ausgefüllt, die die prä- und postallerödzeitliche Entwicklung des Werratales erkennen lassen (Abb. 6). Die beiden Rinnen im Schotterkörper befinden sich an einer schwach konvex gewölbten Stelle des ca. $2 \mathrm{~km}$ breiten Werratalbodens zwischen einem ehemaligen Werralauf im Nordteil der Talaue und dem heutigen (künstlich angelegten?) Werralauf am nördlichen

$\left.{ }^{9}\right)$ Den Herren Eichenberger und Franke von der Werra-Kies AG danke ich sehr herzlich für die jahrelang gewährte freundliche Unterstützung meiner Feldarbeiten. 


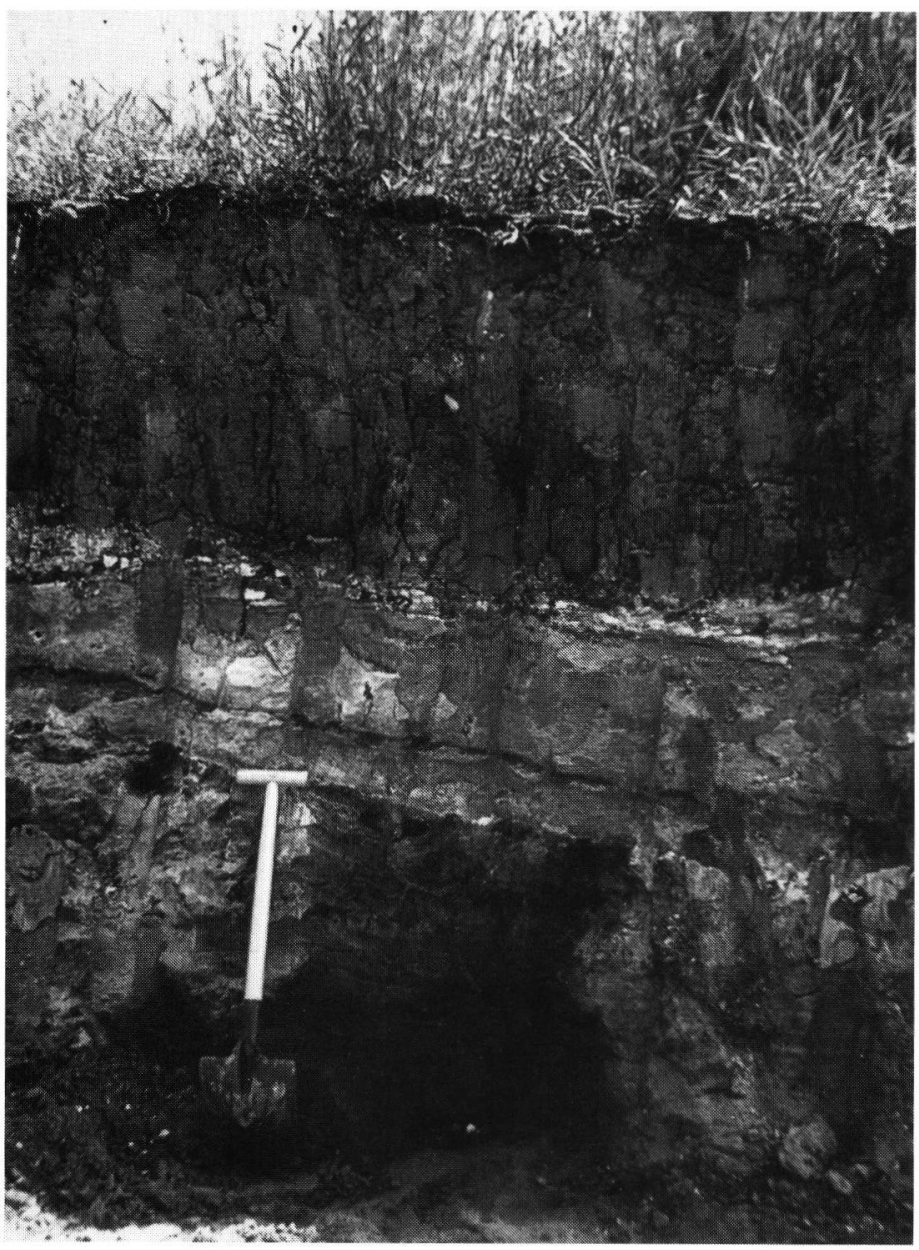

Abb. 9. Laacher See-Bimstuff-Mischsediment von 40 bis $50 \mathrm{~cm}$ Mächtigkeit über dem Spatengriff. Gleiche Lokalität wie bei Abb. 1 und 2. Mischsediment wurde mindestens in zwei Phasen aufgeschüttet. Über dem Mischsediment Auelehm mit dunklem Bt-Horizont. Unter Tuff-Mischsediment geschichtete Sande bis zum Niederterrassen-Schotterkörper. Aufnahme Brosche 1977.

Stadtrand von Eschwege. Abbildung 6 und besonders Abbildung 7 geben den Aufbau der zwei nebeneinander liegenden Rinnen wieder. Es folgen über

(1) dem Niederterrassen-Schotterkörper im vollständigen Profil $\left.{ }^{10}\right)$ :

(2) stark vergleyter, schwach sandiger, blaugrauer Ton mit vielen Rostflecken (diese Serie, die von mir m.W. erstmals im Werratal an verschiedenen Stellen gefunden wurde, nenne ich „Unterer Ried“, im Gegensatz zum „Oberen Ried“ weiter oberhalb);

10) Cornelia Martins, Ina Michalski und Joachim Thiel, alle Berlin, danke ich für die Hilfe bei den Geländeaufnahmen in dieser Grube. 
(3) allerödzeitlicher Laacher Bimstuff in wechselnder Mächtigkeit von 20-60 cm Dicke. (Der Tuff enthält die typischen Minerale des Laacher Bimstuffes, nämlich Augit, Biotit, braune Hornblende und Titanit in reichlicher Menge. Außerdem sind noch Zirkon, Turmalin und Apatit von Herrn Dr. Scheer nachgewiesen worden.);

(4) „Oberer Ried“ mit einem recht frischen, stark wasserhaltigen Baumstamm (Es ist in diesem Fall als blaugrauer sandiger Ton entwickelt, der wie das „Untere Ried“ Pseudovergleyungserscheinungen aufweist);

(5) rötlich-brauner Auesand in wechselnder Mächtigkeit;

(6) unterer rötlich-brauner Auelehm mit einem kräftigen fossilen $A_{h}$-Horizont (AuenSchwarzerde des Atlantikums und Boreals?);

$(7,8)$ oberer rötlich-brauner Auelehm mit einer schwach entwickelten Parabraunerde (Parabraunerde-Vega mit $A_{h^{-}}, A_{e}$ - und $B_{t}$-Horizont - Abb. 8 u. 9.).

Aus den Lagerungsverhältnissen der Schichten 1-7 läßt sich auf folgende morphologische Prozesse schließen (vgl. Abb. 6 und 7):

1. Nach Ablagerung des Niederterrassen-Werraschotterkörpers (Abb. 6a) bildeten sich nebeneinander zwei Rinnen von kaum differierender Breite (Abb. 6b). Dieser Vorgang wird sehr wahrscheinlich mit der ersten glazialen Degradation des Dauerfrostbodeñs im Zusammenhang stehen, als sich erstmalig ein Grundwasserkörper entwickelte und die Werra erstmalig für einen längeren Zeitraum zu einem perennierenden Gerinne wurde, das sich eine zumindest für längere Zeit benutzte Rinne schuf (Datierung: wahrscheinlich Bölling-Interstadial).

2. Es kam zu einer Verfüllung dieser Rinnen durch Ablagerung von Stillwassersedimenten (von sandigen Tonen mit Pflanzenresten), die später pseudovergleyten oder vergleyten (Abb. 6c). Eventuell geschah die Verfüllung als Folge eines Verlassens dieser Rinnen durch die Werra, vielleicht als Folge einer Mäanderverlagerung in nördlichere Richtung (Datierung: Ende des Bölling-Interstadials, ältere Tundrenzeit, frühe Allerödzeit). Zur Erklärung dieser Veränderung im Flußgeschehen kommt allerdings auch eine Klimaumstellung (zu kaltfeuchten periglazialen Verhältnissen) in Betracht, durch die es wieder zu einem flächenhaften, saisonalen Überfließen von großen Teilen des Werratalbodens kam (ältere Tundrenzeit?).

3. Später wurde die mit „Unterem Ried“ ausgefüllte Rinne wieder von der Werra benutzt, als erneut eine Konzentration des Abflusses auf eine mehr oder weniger ständig durchflossene (perennierende?) Rinne der Werra erfolgte. Dies kann am ehesten mit der neuerlichen Degradation des Dauerfrostbodens am Beginn der Allerödzeit geschehen sein, als sich eventuell (wieder?) ein Grundwasserspiegel und Quellenbildung einstellte (Abb. 6d). Reste des „Älteren Ried“ blieben erhalten.

4. In der mittleren Allerödzeit kommt es zur flächenhaften Verwehung des Laacher Bimstuffes, der auf dem breiten Werraboden durch Wässer der Werra aufgenommen, in die Rinnen verschwemmt und hier in Mächtigkeiten von 0,5-1 m abgelagert wird (Abb. 6e). Eventuell erfolgte die Ablagerung des Laacher Bimstuffes in der genannten Mächtigkeit nur deshalb, weil sich die Werra (erneut?) an anderer Stelle eine kurzzeitig benutzte neue flache Rinne geschaffen hatte, die sie zeitweilig benutzte (In anderen Aufschlüssen wurden mehrere Bimslagen festgestellt, die durch tonig-schluffige Sedimente getrennt wurden ${ }^{11}$ ). Auch diese Beobachtung spricht für die These, daß der Laacher

11) Hugenroth und Meyer (1979) sprechen von „Tuff-Mischsedimenten“, wenn größere Mengen Nicht-Bimsmaterial mit dem Laacher Bimstuff vermengt und in größerer Mächtigkeit in Rinnen angehäuft sind. 
Bims in den Rinnen nicht in autochthoner Lagerung vorkommt, sondern durch Wasser verschwemmt wurde. Im Falle der Abb. 6e tritt allerdings keine Schichtung innerhalb des recht mächtigen Laacher-Bims-Paketes auf.).

5. Am Ende der Allerödzeit oder später kommt es zu einer neuerlichen Benutzung der mit Laacher Bimstuff gefüllten Rinnen und zu einer weitgehenden Ausräumung des bis $1 \mathrm{~m}$ mächtigen Laacher Bimses (Abb. 6f). Nicht auszuschließen ist es, daß auch hierfür die neuerliche Bildung eines Grundwasserkörpers und der damit verbundene perennierende Wasserabfluß nach der Jüngeren Tundrenzeit im Präboreal der Grund ist.

6. In der nächsten Phase setzt die endgültige Verfüllung der Rinnen durch das „Obere Ried“" ein (Abb.6g). Bei diesen Sedimenten handelt es sich um die gleichen, die auch ELLENBERG (1968 a: $673 \mathrm{f}$.) aus dem mittleren Werratal beschreibt. ELLENBERG (1968 a: $637 \mathrm{f}$.) erwähnt dagegen keines der von mir beschriebenen älteren (spätglazialen) Rinnensedimente. Nach ELLENBERG (1970: 907, 909), der auf unveröffentlichte pollenanalytische Untersuchung von Frau Dr. Lange, Berlin, zurückgreift, hat die als schwarzblaue Tone, Torfe, helle Sande oder Kiese vorliegende Riedformation bei Breitungen ein boreales bis subboreales Alter ${ }^{12}$ ). Ein bereits jungtundrenzeitliches oder präboreales Alter ist auszuschließen ${ }^{\mathbf{1 3}}$ ).

Die Zufüllung der Rinnen durch die Riedformation ist mit ELLENBERG (1968a: $763 \mathrm{f}$.) wahrscheinlich darauf zurückzuführen, daß die Werra bei ihrer Tendenz, sich ein festes Flußbett zu schaffen, auf dem flachen, breiten Talboden mäandrierte. Dabei muß sie infolge von Materialverlagerungen auf dem Talgrund flache Altwasserrinnen geschaffen haben, in denen im Stillwassermilieu vor allem Torfwuchs und die Sedimentation von Ton stattfinden konnte, wenn die Werra bei höheren Wasserständen auch diese Talbereiche zeitweilig mit Wasser versorgte. Auf diese Weise wurden die Rinnen langsam mit Riedsedimenten aufgefüllt - freilich nur so lange, wie sich die Werra nicht kräftig in den Talboden eingeschnitten hatte. Denkbar ist m.E. allerdings auch, daß eine schwache Wasserbewegung nur temporär, z.B. bei Starkregen, in den von der Werra verlassenen, alten versumpften Rinnen stattfand, wobei das Wasser nicht durch ,"überschwappendes“ Werrawasser, sondern durch reines Niederschlagwasser geliefert wurde.

7., 8. Im weiteren Verlauf wurden in den Rinnen, wie übrigens auch an verschiedenen Stellen außerhalb der Rinnen, zunächst braun-rötliche Auesande (Abb. 6h) und später ein unterer Auelehm abgelagert (Abb. 6i). Wie auch Abb. 10 zeigt, wurde in diesem Auelehm ein kräftiger Horizont, eine Auen-Schwarzerde, gebildet. Das Alter dieses unteren Auelehms wurde bisher nicht ermittelt; jedoch scheint es möglich zu sein, daß der Auelehm älter als das postglaziale Klimaoptimum ist oder in dieses hineinfällt und daß der kräftige fossile $A_{h}$-Horizont in das holozäne Klimaoptimum fällt. HUGENROT \& MEYER (1979) fanden in gleicher stratigraphischer Position im benachbarten Leinetal bei Edesheim (nordwestl. Northeim) einen kräftigen holozänen $\mathrm{A}_{\mathrm{h}}$-Horizont und einen $\mathrm{B}_{\mathrm{t}}$-Horizont, die beide aus einer Auen-Parabraunerde auf Flutlehm der Jüngeren Trundrenzeit hervorgegangen sind.

12) Vergleichbare Sedimente haben an der Leine ein boreales Alter (HÖVERMANN 1952), an der Saar ein atlantisches Alter (ZANDSTRA 1954), an der Weser ein atlantisches Alter, in einzelnen Fällen ein spätboreales bis subboreales Alter (NIETSCH 1955), an der Grone bei Göttingen ein präboreales bis boreales Alter (WunDERLICH 1963) und an der Unstrut ein atlantisches Alter (SCHULTZ 1964) ergeben (zit. n. ELLENBERG 1970: 909).

13) Im benachbartgen Leinetal gliedern HugENROTH \& MEYER (1979) ein jungtundrenzeitliches Auensediment über dem Laacher Bimstuff aus, das nach oben toniger wird und häufiger in flachen Rinnen vorkommt. 


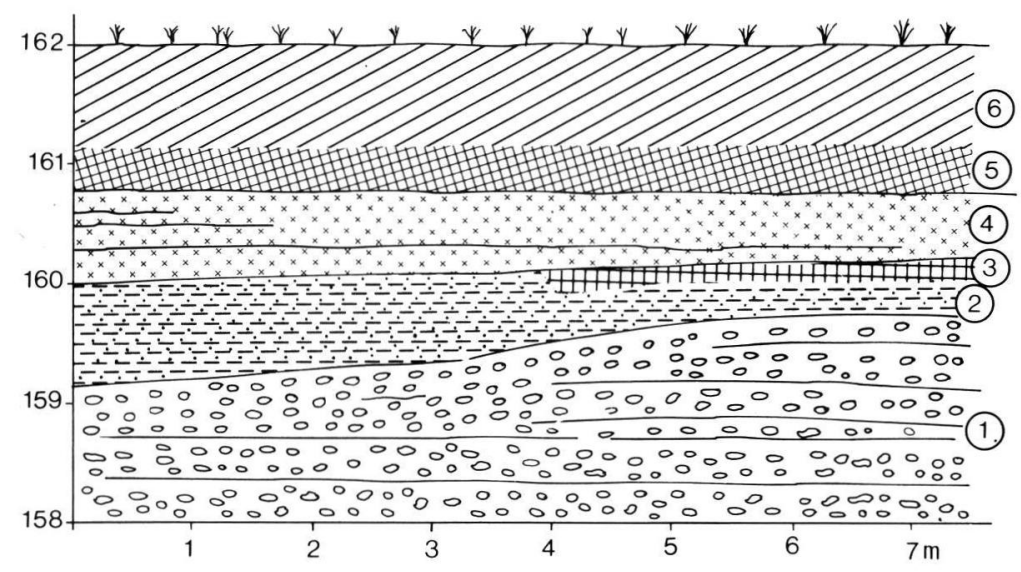

Abb. 10: Niederterrassen-Schotterkörper der Werra mit Deckschichten bei Eschwege (gleiche Lokalität wie bei Abb. 6).

1 = Niederterrassen-Schotterkörper; 2 = gelber, präallerödzeitlicher, wahrscheinlich lößbürtiger Auelehm; 3 = schwache Tonanreicherung im oberen Teil von 2; 4 = Laacher See-Bimstuff (Mischsediment), schwach geschichtet, zu großer Dicke zusammengeschwemmt, in Richtung auf Rinne mächtiger werdend; $5=\mathrm{B}_{\mathrm{t}}$-Horizont; $6=$ Auelehm (undifferenziert).

9. Darauf folgte die Sedimentation des oberen Auelehms, der weitflächig fast über den gesamten Werratalboden ausgebreitet wurde (Abb.6j). Auf ihm ist eine eindeutige Parabraunerde-Vega entwickelt, deren einzelne Horizonte freilich wesentlich schwächer sind als bei einer Parabraunerde auf Löß unter Wald.

\subsection{Schichtfolgen-Variante}

Eine Variante zu dieser Schichtenfolge fand sich in der gleichen Schottergrube bei Eschwege am 19.6.1976 (Abb. 10): Statt der dunklen, tonig-sandigen fleckigen unteren Riedfolge, die stark vergleyt ist und Pflanzenreste enthält (Schicht 2 in Abb. 7), tritt hier ein gelbliches, z.T. grau-rot marmoriertes, entkalktes, lehmig-schluffiges Sediment auf, das wahrscheinlich aus verlagertem Löß besteht. Es ist in Abb. 10 unter dem hellen AllerödBimstuff zu erkennen, wo es Mächtigkeiten von 0,4-0,6 m erreicht. Direkt unter dem Tuff ist dieses gelbe schluffige Sediment polyedrisch und weist Anzeichen einer Tonverlagerung auf. Es muß offen bleiben, ob hier eine allerödzeitliche Bodenbildung vorliegt oder ob durch eine jüngere Tonverlagerung dieser Bereich beeinflußt (u.a. verbraunt) worden ist.

\section{Zusammenfassung}

Über zehnjährige Aufschlußbeobachtungen und -aufnahmen im Werratal zwischen Hannoversch-Münden und Philippsthal (östl. Bad Hersfeld) ließen einige neue Erkenntnisse zum jungpleistozänen und holozänen Flußgeschehen zu. Nach einer Einführung in den morphologischen Formenschatz wird eine 5- bis 8-m-Terrasse beschrieben und mit Hilfe mehrerer Aufschlüsse gezeigt, daß es sich dabei am ehesten um die Würmniederterrasse handelt. Ältere Deutungen einiger Lokalitäten durch MENSCHING (1953), die diese Terrasse zur 
Mittelterrasse rechneten, sind zu revidieren. Niederterrassen können eine ähnliche Decksedimentfolge (Sande, Schwemmschutt, braune Kolluvialmassen) aufweisen wie Mittelterrassen.

Es wurde im Werratal nur ein, z.T. lößbedeckter, würmzeitlicher Niederterrassenkörper gefunden, in den sich schon im oberen Jungwürm nach der Lößterminologie und/oder zu Beginn des Spätglazials die Werra einschnitt. Im Zuge der Bildung eines wahrscheinlich perennierenden Werralaufes in Warmphasen des Spätglazials kam es zu einer Umlagerung von Niederterrassenschottern - entweder flächenhaft oder durch Bildung von $0,5-1,0 \mathrm{~m}$ tiefen Rinnen (Abb. 1 und 2). Eine neue spätglaziale Schuttanlieferung von den Seiten her ist bisher nicht nachzuweisen. Das spätglaziale und frühholozäne Flußgeschehen ließ sich anhand mehrfach sich bietender günstiger Aufschlußverhältnisse bei Eschwege und Schwebda dank des Fundes des Laacher Bimstuffes im Jahre 1974 (Abb. 8 und 9) recht genau verfolgen (Abb. 6 und 7). Die Erkenntnisse von ELLENBERG (1967-1975) und ElLENBERG \& KUHN $(1967,1968)$ zum spätglazialen und frühholozänen Flußgeschehen konnten dadurch verfeinert und zeitlich genauer eingestuft werden (Abb. 6 und 7). Neben einem „Oberen Ried“, das wahrscheinlich dem „Ried" im oberen und mittleren Werragebiet auf dem Gebiet der DDR entspricht, wurde noch unter dem Laacher Bimstuff ein „Unterer Ried“ angetroffen.

In mehrfacher Hinsicht gibt es zum vornehmlich von HugenRoth \& MEYER (1979), MEYER (1982) und WILDHAGEN \& MEYER (1972) untersuchten Leinetal Parallelen. Im Leineund Werratal ist der Laacher See-Bimstuff in Rinnen, z.T. als Mischsediment, weit verbreitet und bildet für das präallerödzeitliche und postallerödzeitliche Flußgeschehen einen wichtigen chronologischen Bezugspunkt. Hier wie dort treten zwischen NiederterrassenSchotterkörper und Laacher See-Bimstuff wahrscheinlich lößbürtige pseudovergleyte Lehme auf.

\section{Schriftenverzeichnis}

Amthauer, H. (1972): Untersuchungen zur Talgeschichte der Oberweser. - Göttinger Geogr. Abh., H. 59; Göttingen.

Brosche, K.-U. \& WaltheR, M. (1980): Lößprofile Vaake und Albungen in Nordhessen. - Geolog. Jahrb. f. Hessen, 108: 143-150; Wiesbaden.

ClaAsen, K. (1941): Die Flußterrassen des Werratals zwischen Bad Sooden-Allendorf und Hannoversch-Münden. - Archiv f. Landes- und Volkskunde v. Niedersachsen, Bd. 1941: 125-166; Hannover.

EllenberG, J. (1968a): Beziehungen zwischen Auslaugung und quartärer Sedimentation im thüringischen Werra-Kaligebiet. - Zeitschr. d. Deutsch. Geol. Ges., Jahrgang 1965, Bd. 117, Hannover 1968: 670-679; Hannover.

- (1968b): Die geologisch-geomorphologische Entwicklung des südwestthüringischen Werragebietes im Pliozän und Quartär. - Diss. Friedrich-Schiller Universität Jena, 1968, 188 S.

- (1969): Die Auslaugungssenke Horschlitt im thüringischen Werra-Kali-Gebiet. - Geologie 18, 4: 488-490; Berlin.

- (1970): Zum Holozän der Werra in Südthüringen. - Wiss. Zeitschr. Friedr. Schiller Univ. Jena, Math.-Nat. Reihe, 19. Jahrgang (1970), H. 5/6: 905-913; Jena.

- (1972): Auslaugung und Sedimentation im Gebiet von Gerstungen. - Geologie 21, 3: 296-304; Berlin.

- (1975): Schwermineralverteilung, Sedimentation und Stratigraphie im Quartär der mittleren Werra. - Zeitschr. Geol. Wiss., 3, 11: 1389-1404; Berlin.

- \& KuHN, G. (1967): Kieselgur im Werra-Kaligebiet. - Hallesches Jahrb. Mitteldeutsch. Erdgesch., 8: 67-86; Leipzig. 
ELlENBERG, J. \& - (1969): Das Quartär und seine nutzbaren Gesteine im Werragebiet. - Exkursionsführer Ergebnisse quartärgeologischer Untersuchungen Thüringen: 5-23; Berlin.

GARLEFF, K. (1976): Beitrag zur Deutung der Terrassen im unteren Werratal. - Eiszeitalter und Gegenwart, 17: 118-124; Öhringen.

GRUPE, O. (1909): Zur Frage der Terrassenbildung im mittleren Flußgebiet der Weser und Leine und ihrer Altersbeziehungen zu den Eiszeiten. Zeitschr. d. Dtsch. Geol. Ges., Bd. 61, Monatsber. Nr. 12: 470-493; Berlin.

- (1911): Über das Alter der Dislokationen des hannoversch-hessischen Berglandes und ihren Einfluß auf Talbildung und Basalteruptionen. - Zeitschr. d. Dtsch. Geol. Ges., Bd. 63: 264-316; Berlin.

- (1912): Die Flußterrassen des Wesergebietes und ihre Altersbeziehungen zu den Eiszeiten. Zeitschr. d. Dtsch. Geol. Ges., Bd. 64: 265-298; Berlin.

- (1926): Tal- und Terrassenbildung im Gebiet der Werra-Fulda-Weser. - Geol. Rdsch. 17: 161-196; Stuttgart.

- (1927): Die Talentwicklung des Wesersystems. - Geol. Rdsch. 18: 456-461; Stuttgart.

HugenRoth, P. \& MeYer, B. (1979): Exkursionsmaterialien anläßlich der Exkursion 21 auf dem 42. Deutschen Geographentag Göttingen am 9. 6. 1979: „,Auenprofil Northeim-Nord“; Göttingen.

KOZARSKI, S. \& ROTNICKI, K. (1977): Valley floors and changes of river channel patterns in the north Polish plain during the late-würm and holocene. - Quaestiones Geographicae 4 UAM: 51-93; Torun/Thorn.

MäCKEL, R. (1970): Untersuchungen zur jungquartären Flußgeschichte der Lahn in der Gießener Talweitung.- Eiszeitalter und Gegenwart, 20: 138-174; Öhringen.

Maier, B. geb. SipPel (1952): Zur Morphologie des Soodener Berglandes. - Göttinger Geogr. Abh. 11; Göttingen.

MeINECKE, F. (1913): Über die Entwicklungsgeschichte des Werratales. - Archiv Landes- u. Volkskunde Prov. Sachsen, 1913: 77-110; Halle.

Mensching, H. (1953): Die periglaziale Formung der Landschaft des unteren Werratales. - Göttinger Geogr. Abh. 14: 79-128; Göttingen.

MeYeR, B. (1982): In „Manuskriptsammlung der Vorträge im Rahmen der 9. Tagung des AK Geomorphologie vom 11. 10.-15. 10. 1982 in Braunschweig": X 57-X 87; Braunschweig.

RiCKEN, W., (1982a): Quartäre Klimaphasen und Subrosion als Faktoren der Bildung von KiesTerrassen im südwestlichen Harzvorland. - Eiszeitalter und Gegenwart, 32: 109-136; Hannover.

- (1982 b): Mittel- und jungpleistozäne Lößdecken im südwestlichen Harzvorland. Stratigraphie, Paläopedologie, fazielle Differenzierung und Konnektierung mit Flußterrassen. - In: BORK \& RICKEN: Bodenerosion, holozäne und pleistozäne Bodenentwicklung. - Catena Supplement 3; Braunschweig.

- \& MeYer, B. (1982): Exkursion III. Südwestliches Harzvorland. In: „Manuskriptsammlung der Vorträge im Rahmen der 9. Tagung des AK Geomorphologie vom 11. 10.-15.10. 1982 in Braunschweig": X 57-X 87; Braunschweig.

RoHDEnBuRG, H. (1965): Untersuchungen zur pleistozänen Formung am Beispiel der Westabdachung des Göttinger Waldes. - Gießener Geogr. Schr., H. 7; Gießen.

- (1966): Eiskeilhorizonte in südniedersächsischen und nordhessischen Lößprofilen. - Mitt. d. Dtsch. Bodenkdl. Ges. 5: 137-170; Göttingen.

- (1968): Jungpleistozäne Hangformung in Mitteleuropa. - Beiträge zur Kenntnis, Deutung und Bedeutung ihrer räumlichen und zeitlichen Differenzierung. - Göttinger Bodenkundl. Ber., 6: 3-107; Göttingen. 
SEMmEL, A. (1972 a): Unterschungen zur jungpleistozänen Talentwicklung in deutschen Mittelgebirgen. - Zeitschr. f. Geomorph., N.F., Supplementband 14: 105-112; Berlin -Stuttgart.

- (1972 b): Geomorphologie der Bundesrepublik Deutschland. - Geographische Zeitschrift, Beihefte, 149 S.; Wiesbaden.

- (1974): Der Stand der Eiszeitforschung im Rhein-Main-Gebiet. In: SEMmel, A. (Hrsg.): Das Eiszeitalter im Rhein-Main-Gebiet. - Rhein.-Main. Forsch., 78: 215 S.; Frankfrut a. M.

SIEGERT, L. (1921): Beiträge zur Kenntnis des Pliozäns und der diluvialen Terrassen im Flußgebiet der Weser. - Abh. d. Preuß. Geol. Landesanst., N.F., 90, 130 S.; Berlin.

- (1912): Über die Entwicklung des Wesertales. - Zeitschr. d. Dtsch. Geol. Ges., 64: 233-264; Berlin.

SoERgel, W. (1921): Die Ursachen der diluvialen Aufschotterung und Erosion. Berlin.

- (1927: Zur Talentwicklung des Werra-Weser- und des Ilm-Saale-Systems. - Geol. Rundschau, 18: 103-120; Stuttgart.

Wildhagen, H. \& MeYer, B. (1972): Holozäne Boden-Entwicklung, Sediment-Bildung und Geomorphogenese im Flußauen-Bereich des Göttinger Leinetal-Grabens. 1: Spätglazial und Holozän bis zum Beginn der eisenzeitlichen Auenlehm-Ablagerung. 2: Die Auenlehm-Decken des Subatlantikums. - Göttinger Bodenkd. Ber. 21: 1-75 und 77-158; Göttingen.

Manuskript eingegangen am 2.1.1984, Nachträge April 1984. 
